\title{
Effects of brown coatings on the absorption enhancement of black carbon: a numerical investigation
}

\author{
Jie Luo, Yongming Zhang, Feng Wang, and Qixing Zhang \\ State Key Laboratory of Fire Science, University of Science and Technology of China, Hefei, Anhui 230026, China
}

Correspondence: Qixing Zhang (qixing@ustc.edu.cn)

Received: 17 June 2018 - Discussion started: 29 June 2018

Revised: 9 November 2018 - Accepted: 12 November 2018 - Published: 29 November 2018

\begin{abstract}
Using the numerically exact multiple sphere Tmatrix (MSTM) method, we explored the effects of brown coatings on absorption enhancement $\left(E_{\mathrm{abs}}\right)$ of black carbon (BC) at different wavelengths $(\lambda)$. In addition, the ratio of the absorption of $\mathrm{BC}$ coated by brown carbon $(\mathrm{BrC})$ to an external mixture of $\mathrm{BrC}$ and $\mathrm{BC}\left(E_{\mathrm{abs} \_ \text {internal }}\right)$ is also investigated. In this work, thinly coated $\mathrm{BC}$ is defined as that with a BC volume fraction over $20 \%$, and other $\mathrm{BC}$ is considered to be thickly coated. $E_{\text {abs }}$ increases with the absorption of coatings, while an opposite trend is observed for $E_{\text {abs_internal }}$. A much wider range of $E_{\text {abs }}$ is observed for BC with brown coatings compared to that with non-absorbing coatings. As the mass ratio of $\mathrm{BrC}$ to $\mathrm{BC}\left(M_{\mathrm{R}}\right)$ is over 13.9, $E_{\text {abs }}$ can exceed 5.4 for BC with brown coatings at $\lambda=0.35 \mu \mathrm{m}$ under a typical size distribution. Specifically, as $M_{\mathrm{R}}$ increases to approximately $13.9, E_{\mathrm{abs}}$ values of larger than 3.96 can be observed at $0.532 \mu \mathrm{m}$, which is a little higher than the commonly measured $E_{\text {abs }}$ of $1.05-3.5$ at this wavelength. Previous studies have focused on the lensing effects of coatings but neglected the blocking effects of absorbing coatings. $E_{\text {abs_internal }}$ can be below 1 at an ultraviolet spectral region for $\mathrm{BC}$ with brown coatings, which indicates that the absorption of internally mixed $\mathrm{BC}$ is less than that of an external mixture of $\mathrm{BrC}$ and $\mathrm{BC}$ due to the blocking effects of outer coatings, and we named the blocking effect of absorbing coatings the "sunglasses effect". In addition, the applicability of a core-shell sphere model is also evaluated for $\mathrm{BC}$ with brown coatings. The absorption cross section $\left(C_{\mathrm{abs}}\right)$ of thickly coated BC is underestimated by the core-shell sphere model for all wavelengths while the underestimation becomes negligible as the imaginary part of the refractive index of brown carbon $\left(k_{\mathrm{BrC}}\right)$ becomes very large. The lensing effect and the sunglasses effect are clearly defined. Moreover, the effects of composition ratios and the size distribution are
\end{abstract}

explored at different wavelengths. Our findings can improve the understanding of the absorption enhancement of $\mathrm{BC}$ with brown coatings.

\section{Introduction}

Recent modeling and field studies have indicated that aerosol light absorption is an important contributor to climate forcing (Jacobson, 2001; Krishnan and Ramanathan, 2002; Bond et al., 2013). Black carbon (BC), which is a product of incomplete combustion, is the strongest solar-absorbing aerosol in the atmosphere (Lack et al., 2009; Zhang et al., 2008b). BC radiative forcing from fossil fuels and biomass burning has been estimated to be approximately $0.4 \mathrm{~W} \mathrm{~m}^{-2}$, as the second anthropogenic contributor (after $\mathrm{CO}_{2}$ ) to climate forcing due to its strong absorption of solar radiation (Forster et al., 2007; Schwarz et al., 2008). Sensitivity tests suggest that the mixing state and morphology of $\mathrm{BC}$ aerosols can largely affect the absorption of BC (Ma et al., 2012; Zhang et al., 2018). Due to the large uncertainties of $\mathrm{BC}$ morphologies and mixing states, the understanding of $\mathrm{BC}$ absorption is still limited. Even when coated with nonabsorbing materials, the $\mathrm{BC}$ absorption can be enhanced (Liu et al., 2017; Cappa et al., 2012). Many studies mainly attribute the absorption enhancements ( $\left.E_{\text {abs }}\right)$ to the lensing effect (Bond et al., 2006; Fuller et al., 1999b).

For the estimation of $\mathrm{BC}$ absorption enhancements, many field measurements have been conducted. Naoe et al. (2009) presented factors of 1.1-1.4 for BC absorption enhancement at a suburban site in Japan, while Cui et al. (2016) indicated that the absorption enhancement factors increase from $1.4 \pm 0.3$ during fresh combustions to $\sim 3$ for aged $\mathrm{BC}$ at a rural site over the North China Plain (NCP). Liu et al. (2017) 
found that $\mathrm{BC}$ absorption enhancement is significantly influenced by the particle mixing state. The measured range of $E_{\mathrm{abs}}$ is approximately 1-1.5. You et al. (2016) observed the wavelength-dependent absorption enhancement of coated BC. In their measurements, $E_{\text {abs }}$ increased up to 3 at the shortest measured wavelengths, while it was approximately 1.6 in the near-IR wavelength. A negligible absorption enhancement of only $6 \%$ for ambient BC particles was reported by Cappa et al. (2012) based on direct measurements over California (USA). Chen et al. (2017) reported an average $E_{\text {abs }}$ of $2.07 \pm 0.72$ for the urban haze in winter in northern China. However, this result was time dependent. The absorption enhancement of $\mathrm{BC}$ during the urban $\mathrm{PM}_{2.5}$ pollution was $1.31 \pm 0.29$ in the morning, while in the afternoon, it increased to approximately $2.23 \pm 1.05$; then, it decreased to $1.52 \pm 0.75$ in the evening. Recently, a larger $E_{\text {abs }}$ value of 2.6-4.0 at Beijing, China, was reported by Xu et al. (2016). In summary, the reported $E_{\text {abs }}$ values are not consistent in different studies due to the complex aging statuses.

Although the field measurements can provide referential absorption enhancement values for different aging statuses and regions, causes of these enhancements are not clear. For example, what is the main factor that causes complex absorption enhancements: morphology, the mixing states or the types of coatings? To our best knowledge, field measurements currently have difficulty answering these questions. Numerical simulation is a strong tool that reveals the mechanism responsible for the complex absorption enhancements. To improve the understanding of the complex absorption enhancements of $\mathrm{BC}$, numerical studies have also been conducted. For instance, based on the core-shell Mie theory, the absorption enhancement factors have been estimated up to 3 (Bond et al., 2006). By the numerically exact multiple sphere T-matrix (MSTM) method, Zhang et al. (2017) presented the absorption enhancements of non-absorbing coatings for aged $\mathrm{BC}$ ranging from 1.1 to 2.4 , and they were significantly influenced by the morphology and aging statuses but insensitive to the $\mathrm{BC}$ refractive index. However, previous studies have failed to uncover the effects of coating absorption. In their studies, coatings were considered to be non-absorptive, and BC absorption enhancements were completely caused by lensing effects. Nevertheless, in the atmosphere, there is a type of organic carbon (OC) that absorbs the radiation in the range of the ultraviolet and visible spectra, which is known well as brown carbon $(\mathrm{BrC})$; $\mathrm{BC}$ can also be mixed with $\mathrm{BrC}$. Compared with non-absorbing materials, the absorption of $\mathrm{BrC}$ is significantly wavelength dependent and the imaginary part of the refractive index for $\mathrm{BrC}$ has a wide range (Kirchstetter et al., 2004), which results in large uncertainties for the estimation of aerosol absorption. Therefore, the absorption of $\mathrm{BrC}$ has gained increasing interest (Kirchstetter et al., 2004; Shamjad et al., 2018).

Many studies have been conducted to evaluate the absorption of $\mathrm{BrC}$. One typical method for the determination of $\mathrm{BrC}$ absorption is isolating $\mathrm{BrC}$ by extracting filtered sam- ples (Cheng et al., 2017). This method can be used to determine the imaginary part of the $\mathrm{BrC}$ refractive index. However, it is difficult to understand the effects of $\mathrm{BrC}$ on the total aerosol absorption, as $\mathrm{BrC}$ is commonly mixed with other chemical compositions. The assumption of externally mixing can be used to evaluate the absorption of $\mathrm{BrC}$ and $\mathrm{BC}$ separately. Nevertheless, in many cases, BC is internally mixed with other materials. It is widely accepted that the absorption is underestimated by the external mixing assumption when $\mathrm{BC}$ is coated with non-absorbing materials due to lensing effects. However, whether this is true for $\mathrm{BC}$ with $\mathrm{BrC}$ coatings is not clear. To understand the effects of $\mathrm{BrC}$ coatings, the contributions of "lensing effects" and the total absorption enhancement of $\mathrm{BC}$ with $\mathrm{BrC}$ coatings should be analyzed individually.

Cheng et al. (2017) has conducted a numerical investigation on $\mathrm{BC}$ absorption enhancement, BrC absorption enhancement, and lensing effects on $\mathrm{BC}$ mixed with $\mathrm{BrC}$ by assuming a core-shell structure. While the internal mixing of BC is widely accepted, the core-shell structure is debated (Adachi et al., 2010; Cappa et al., 2012; Bond et al., 2013). He et al. (2015) developed a theoretical BC aging model and concluded that the evolution of coating thickness, morphology, and composition during the aging process could have significant impacts on BC absorption. Freshly emitted BC commonly presents fractal structures. As the $\mathrm{BC}$ ages in the atmosphere, $\mathrm{BC}$ becomes more compact and $\mathrm{OC}$ materials can condense onto the particles. Therefore, $\mathrm{BC}$ can be embedded in an OC shell (China et al., 2013; Wang et al., 2017). When the non-BC fraction is low, BC can still present a nearfractal structure (referred to as thinly coated BC in this study) (Wang et al., 2017). As BC is further coated, BC aggregates are collapsed into more compact and spherical clusters when fully engulfed in coating material (referred to as thickly coated BC in this study) (Coz and Leck, 2011a; Zhang et al., 2008a).

In this study, a numerical investigation was conducted to explore the factors that contribute to the complex absorption enhancement of $\mathrm{BC}$ with $\mathrm{BrC}$ coatings for different mixing states. Two types of mixing states were considered: thinly coated BC and thickly coated BC. Thinly coated BC is assumed to be those with a $\mathrm{BC}$ volume fraction over $20 \%$, and the other $\mathrm{BC}$ is considered to be thickly coated. The results would give further understanding for the causes of $\mathrm{BC}$ absorption enhancements and suggestions for the inferred $\mathrm{BC}$ mixing states.

\section{Methodology}

\subsection{Geometric properties of $\mathrm{BC}$ aerosols}

In climate modeling, a spherical shape is commonly assumed for aerosols and can be calculated with high efficiency using the Mie theory (Mie, 1908). However, in many cases, 
this shape can introduce large errors compared with the measurements due to the oversimplification of the shape. Recently, the nonsphericity of aerosols has gained increasing interest (Yang et al., 2003; Bi and Yang, 2016). Specifically, observations have indicated that uncoated BC particles are commonly composed of numerous small spherical particles. Fractal aggregates can be greatly used to describe their geometric properties. Mathematically, the structure satisfies the well-known fractal law (Mishchenko et al., 2002):

$$
\begin{aligned}
& n_{s}=k_{0}\left(\frac{R_{\mathrm{g}}}{R}\right)^{D_{\mathrm{f}}}, \\
& R_{\mathrm{g}}^{2}=\frac{1}{n_{s}} \sum_{i=1}^{n_{s}} l_{i}^{2},
\end{aligned}
$$

where $n_{s}$ represents the number of the monomers in the cluster, $R$ represents the mean radius of the monomers, $k_{0}$ represents the fractal prefactor, $D_{\mathrm{f}}$ represents the fractal dimension, $R_{\mathrm{g}}$ represents the radius of gyration, and $l_{i}$ represents the distance from the $i$ th monomer to the center of the cluster.

The fractal dimension is a key parameter that describes the compactness of BC aggregates (Sorensen, 2001; Sorensen and Roberts, 1997; Luo et al., 2018a). Generally, aggregates tend to be more compact with the increase in $D_{\mathrm{f}}$. A $D_{\mathrm{f}}$ of 1 can describe an open-chain-type shape, while the aggregates tend to be spherical as $D_{\mathrm{f}}$ approaches 3 . Numerous experimental studies have been carried out to evaluate the $D_{\mathrm{f}}$ of BC aggregates. Immediately after they are emitted, BC aggregates generally exhibit fluffy structures with a small fractal dimension $\left(D_{\mathrm{f}}\right)$, that is normally less than 2 , such as the $D_{\mathrm{f}}$ of BC aggregates from biomass burnings (1.67-1.83) (Chakrabarty et al., 2006), the $D_{\mathrm{f}}$ of BC from vehicle emissions (1.52-1.94) (China et al., 2014), and the $D_{\mathrm{f}}$ of BC from diesel combustion (1.6-1.9) (Wentzel et al., 2003).

However, under the effects of atmospheric aging, the structures and chemical compositions of BC may change. Aged $\mathrm{BC}$ tends to be mixed with other chemical components, and the shape becomes more compact. Therefore, in the atmosphere, aggregates can have fractal dimensions of up to 2.6 (Chakrabarty et al., 2006). In some cases, BC aggregates are thinly coated with other materials and still exhibit a fractal structure. However, different from freshly emitted BC aggregates, both lacy and compact structures can exist. Therefore, for thinly coated $\mathrm{BC}$, the $D_{\mathrm{f}}$ was assumed to be in the range from 1.8 to 2.6. As $\mathrm{BC}$ becomes increasingly coated, BC aggregates may transform from highly agglomerated to nearly spherical particles. A $D_{\mathrm{f}}=2.6$ was assumed for thickly coated BC. Even though a fractal prefactor can also vary under different combustion and aging statuses, it has less significant effects on the absorption of BC compared to the $D_{\mathrm{f}}$. When fixing $D_{\mathrm{f}}$ to be 1.82 , Liu and Mishchenko (2005) demonstrated that the absorption cross section of BC aggregates does not change substantially as the fractal prefactor varies from 0.9 to 2.1 . Therefore, a fixed fractal prefactor of 1.2 was assumed in this work.
Table 1. Morphological parameters of $\mathrm{BC}$ aerosols, where $f_{\mathrm{BC}}$ represents the volume fraction of $\mathrm{BC}$.

\begin{tabular}{lrr}
\hline Parameters & Thinly coated BC & Thickly coated BC \\
\hline$k_{o}$ & 1.2 & 1.2 \\
$n_{S}$ & $1-1000$ & $1-1000$ \\
$D_{\mathrm{f}}$ & $1.8,2.2,2.6$ & 2.6 \\
$f_{\mathrm{BC}}$ & $0.2,0.4,0.6,0.8,1.0$ & $0.05,0.06,0.075,0.1$ \\
\hline
\end{tabular}

The monomer radius and monomer number are two key parameters that determine the particle size. Even though the monomers' radii are polydispersed in the atmosphere, they vary within a narrow range. Monomer radii are commonly observed within $\sim 10-25 \mathrm{~nm}$ (Bond and Bergstrom, 2006). In addition, Kahnert (2010b) demonstrated that $C_{\text {abs }}$ is insensitive to monomer radii when the monomer radii are within $\sim 10-25 \mathrm{~nm}$. As a result, for convenient application, a fixed monomer radius of $R=20 \mathrm{~nm}$ was assumed in this work. Based on transmission electron microscopy (TEM) and scanning electron microscopy (SEM) imaging, the monomer number $n_{s}$ can reach approximately 800 (Adachi and Buseck, 2008). Values of $1 \leq n_{s} \leq 1000$ were considered in this work. For an aggregate with $n_{s}$ monomers, the equivalent radius was given by the equivalent volume sphere radius $R \sqrt[3]{n_{s}}$. The morphological parameters considered in this work are shown in Table 1.

\subsection{Generation of $\mathrm{BC}$ aerosols}

The morphologies of coated BC considered in this work are classified into two categories: thinly coated BC and thickly coated BC. The closed-cell structure, which is an example of where coating material that not only covers the outer layers of BC aggregates but also fills the internal voids among primary spherules, can be used to represent the thinly coated BC (Liou et al., 2011; Strawa et al., 1999). In addition, Kahnert (2017) demonstrated that the absorption of closed-cell structures and more realistic morphologies do not have large deviations. Therefore, it is reasonable to use the closed-cell model for calculating the absorption of thinly coated $\mathrm{BC}$, while the thickly coated $\mathrm{BC}$ is commonly represented by a structure in which BC aggregates are encapsulated in a sphere (Zhang et al., 2017; Cheng et al., 2014). The typical morphologies are shown in Fig. 1.

Diffusion-limited algorithms (DLAs), including the particle-cluster aggregation (PCA) (Hentschel, 1984) and the cluster-cluster aggregation (CCA) methods (Thouy and Jullien, 1994), have been developed for the generation of aggregates. However, adjustable DLA codes are commonly applied due to their quick implementation and adjustable fractal parameters (Koylu et al., 1995). In this work, an adjustable DLA code developed by Woźniak (2012) was used. Compared with ordinary DLA codes, this code preserves fractal parameters during each step of the aggrega- 


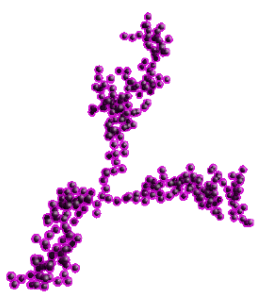

(a) Thinly coated, $D_{f}=1.8$

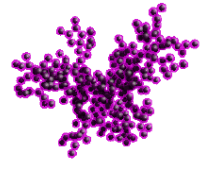

(b) Thinly coated, $D_{f}=2.2$

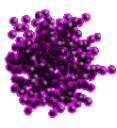

(c) Thinly coated, $D_{f}=2.6$

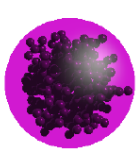

(d) Thickly coated, $D_{f}=2.6$

Figure 1. Typical morphologies of BC, $n_{s}=300, k_{0}=1.2$.

tion, which avoids the generation of multifractal aggregates (Jensen et al., 2002). After the generation of the aggregates, the coatings were added. More specifically, for thinly coated $\mathrm{BC}$, the $\mathrm{BrC}$ shells were generated by the adjustable algorithm, and then the $\mathrm{BC}$ cores were added; the details are shown in previous studies (Luo et al., 2018c; Wu et al., 2014). The thickly coated BC is generated by covering the $\mathrm{BrC}$ spherical coatings on the $\mathrm{BC}$ aggregates, as shown in the study of Cheng et al. (2015).

\subsection{Light scattering method}

To calculate the radiative properties of $\mathrm{BC}$ in this work, numerical solution methods from Maxwell's equations, including the finite-difference time-domain (FDTD) method (Yee, 1966; Taflove and Hagness, 2005), generalized multiparticle Mie (GMM) method (Xu, 1997; Xu and Gustafson, 2001), MSTM method (Mackowski and Mishchenko, 2011; Mishchenko et al., 2004), the geometric-optics surface-wave (GOS) method (Liou et al., 2011; He et al., 2016), and discrete-dipole approximation (DDA) method (Draine and Flatau, 1994; Laczik, 1996; Yurkin and Hoekstra, 2007), can all be used. However, compared with other numerical methods, the MSTM has an advantage for the calculation of optical properties for randomly oriented particles analytically without numerically averaging over particle orientations. Therefore, this method has high efficiency to calculate optical properties of BC. In this work, the latest MSTM code, MSTM version 3.0 (Mackowski, 2013), was applied.

In this study, all the radiative properties of $\mathrm{BC}$ were calculated based on the assumption that BC particles and their mirror counterparts are present in equal numbers in the ensemble of randomly oriented particles. In the atmosphere, it is reasonable to assume that the possibility of each particle direction is identical, which mathematically satisfies the definition of random orientation (Mishchenko and Yurkin, 2017).

\subsection{Calculating absorption enhancement of BC}

The presence of non-BC-coated materials can result in the enhancement of $\mathrm{BC}$ absorption, referred to as $\mathrm{BC}$ absorption enhancement $\left(E_{\text {abs }}\right)$. Therefore, $E_{\text {abs }}$ can be defined as the amplification of $\mathrm{BC}$ absorption after $\mathrm{BC}$ being coated:

$E_{\text {abs }}=\frac{C_{\text {abs_coated }}}{C_{\text {abs_bare }}}$,

where $C_{\text {abs_coated }}$ and $C_{\text {abs_bare }}$ represent the absorption cross sections of coated $\mathrm{BC}$ and bare $\mathrm{BC}$, respectively.

As $\mathrm{BrC}$ also absorbs solar radiation, it is also desirable to compare the absorption of $\mathrm{BC}$ coated by $\mathrm{BrC}$ coatings with $\mathrm{BC}$ and an external mixture of $\mathrm{BrC}$ and $\mathrm{BC}$. The absorption of the $\mathrm{BrC}$ shell is calculated as

$C_{\text {abs_BrC_shell }}=C_{\text {abs_BrC(coated shape })}-C_{\text {abs_BrC(bare shape) }}$,

where $C_{\text {abs_BrC(coated shape) }}$ and $C_{\text {abs_BrC(bare shape) }}$ represent the absorption cross sections of $\mathrm{BrC}$ with morphologies that are identical to coated $\mathrm{BC}$ and bare $\mathrm{BC}$, respectively. The calculation of the absorption of $\mathrm{BrC}$ shell is shown in Fig. S1 in the Supplement. In this process, we assume that the absorption of $\mathrm{BrC}$ with the same shape as the coated $\mathrm{BC}$ is identical to the external mixture of $\mathrm{BrC}$ that has the same shape as bare $\mathrm{BC}$ and $\mathrm{BrC}$ shell. We must clarify that this disposal method neglects the blocking effect and lensing effect of the outer $\mathrm{BrC}$ shell on the internal $\mathrm{BrC}$. However, as the $\mathrm{BrC}$ absorption is significantly less than the $\mathrm{BC}$ absorption with an identical shape, the absorption caused by the blocking effect and lensing effect of outer $\mathrm{BrC}$ on the internal $\mathrm{BrC}$ is relatively small compared with the BC absorption. Therefore, it is reasonable to make some simplifications.

In this work, we defined a parameter $\left(E_{\text {abs_internal }}\right)$ to represent the ratio between the absorption of $\mathrm{BC}$ coated by $\mathrm{BrC}$ coatings and an external mixture of $\mathrm{BrC}$ and $\mathrm{BC}$ :

$E_{\text {abs_internal }}=\frac{C_{\text {abs_coated }}}{C_{\text {abs_BrC_shell }}+C_{\text {abs_bare }}}$.

\subsection{Size distribution}

The absorption of BC is significantly affected by the particle size (Kahnert, 2010b; Luo et al., 2018b). Therefore, the effects of the size distribution on $\mathrm{BC}$ absorption enhancement should be considered carefully. The shape of BC particles is commonly irregular. To describe the size of each BC particle, the radius of the corresponding equivalent volume 
sphere is typically used. Based on numerous measurements, a lognormal size distribution is observed to fit the realistic BC size distributions well (Bond et al., 2002; Chakrabarty et al., 2006; Wang et al., 2015), and it is widely used in climate models for the estimation of $\mathrm{BC}$ radiative forcing (Moffet and Prather, 2009; Chung et al., 2012). However, the mean size and standard deviation vary with the combustion status and aging status. In the atmosphere, geometric mean radii $\left(r_{\mathrm{g}}\right)$ between 0.05 and $0.06 \mu \mathrm{m}$ for BC are widely accepted (Alexander et al., 2008; Coz and Leck, 2011b; Liu et al., 2018; Li et al., 2016). The geometric standard deviation $\left(\sigma_{\mathrm{g}}\right)$ varies within a relatively narrow range. Consequently, bare $\mathrm{BC}$ with $r_{\mathrm{g}}$ between 0.03 and $0.1 \mu \mathrm{m}$ is considered for sensitivity analysis, an $\sigma_{\mathrm{g}}$ from 1.15 to 1.75 . The minimum and maximum equivalent volume radii are $r_{\min }=0.02 \mu \mathrm{m}$ and $r_{\max }=0.2 \mu \mathrm{m}$, respectively.

To estimate the effects of coating thickness on the absorption properties of $\mathrm{BC}$, we assumed that $\mathrm{BrC}$ coating ratios are independent of $\mathrm{BC}$ size. The difference between the size distributions of bare $\mathrm{BC}$ and coated $\mathrm{BC}$ is attributed to the coating thickness. The size distribution of bare and coated $\mathrm{BC}$ is shown in Fig. S2. Even though the assumption does not completely agree with the real cases, it is reasonable to make some simplifications for the sensitivity analysis. Here, we must clarify that the size distribution parameters $\left(r_{\mathrm{g}}\right.$ and $\sigma_{\mathrm{g}}$ ) mentioned in this work are applied for the bare $\mathrm{BC}$, and the overall effective volume radius of coated $\mathrm{BC}$ is equal to the sum of coating thickness and radius of bare $\mathrm{BC}$.

\subsection{Calculation of bulk radiative properties of $\mathrm{BC}$}

To make our work more consistent with real circumstance, bulk optical properties are considered. These properties are calculated by averaging over a certain particle size distribution. In application, the equivalent volume radii $(r)$ of $\mathrm{BC}$ are commonly assumed to follow a lognormal size distribution:

$$
n(r)=\frac{1}{\sqrt{2 \pi} r \ln \left(\sigma_{\mathrm{g}}\right)} \exp \left[-\left(\frac{\ln (r)-\ln \left(r_{\mathrm{g}}\right)}{\sqrt{2} \ln \left(\sigma_{\mathrm{g}}\right)}\right)^{2}\right],
$$

where $r_{\mathrm{g}}$ and $\sigma_{\mathrm{g}}$ represent the geometric mean radius and geometric standard deviation, respectively. Given the size distribution, the bulk $C_{\mathrm{abs}}$ can be obtained using the following equation:

$$
<C_{\mathrm{abs}}>=\int_{r_{\min }}^{r_{\max }} C_{\mathrm{abs}}(r) n(r) \mathrm{d} r .
$$

The bulk $E_{\text {abs }}$ and $E_{\text {abs_internal }}$ are calculated as those in Eqs. (3)-(5). The only difference is that the absorption cross section is now the bulk absorption cross section.

\section{Results}

\subsection{Effects of the imaginary part of the $\mathrm{BrC}$ refractive index: lensing effect and sunglasses effect}

The refractive index of $\mathrm{BC}$ is commonly assumed to be wavelength independent over the visible and near-visible spectral regions, and the imaginary part $k_{\mathrm{BC}} \approx 0.79$ (Moosmuller et al., 2009; Bond and Bergstrom, 2006). In addition, Zhang et al. (2017) have demonstrated that the uncertainties of the $\mathrm{BC}$ refractive index have little impact on the absorption enhancement of coated $\mathrm{BC}$ aggregates. Therefore, a typical refractive index $m=1.95+0.79 i$ of $\mathrm{BC}$ was adopted in this study.

The real parts of the $\mathrm{BrC}$ refractive indices were assumed to have a constant value of 1.5 (Schnaiter et al., 2005), while the imaginary part of the refractive index $\left(k_{\mathrm{BrC}}\right)$ was significantly dependent on wavelength at shorter visible and ultraviolet (UV) wavelengths (Moosmuller et al., 2009; Andreae and Gelencser, 2006; Alexander et al., 2008). Figure 2 shows the effects of $k_{\mathrm{BrC}}$ on $E_{\mathrm{abs}}$ and $E_{\text {abs_internal }}$, where $f_{\mathrm{BC}}$ represents the $\mathrm{BC}$ volume fraction. Large deviations in $E_{\mathrm{abs}}$ and $E_{\mathrm{abs} \_ \text {internal }}$ can be observed given different values of $k_{\mathrm{BrC}}$. Generally, $E_{\mathrm{abs}}$ increases with $k_{\mathrm{BrC}}$, while $E_{\text {abs internal }}$ decreases with increasing $k_{\mathrm{BrC}}$. Therefore, it is desirable to evaluate the effects of absorbing coatings on $\mathrm{BC}$ absorption enhancement. Given identical $k_{\mathrm{BrC}}$ values, the absorption enhancements of thickly coated $\mathrm{BC}$ increase with wavelength. However, for $\mathrm{BC}$ that is internally mixed with $\mathrm{BrC}$, wavelength-dependent absorption enhancements are measured to decrease with $\lambda$ (You et al., 2016). This may be due to the wavelength-dependent $k_{\mathrm{BrC}}$. For thickly coated BC, $E_{\text {abs_internal }}$ and $E_{\text {abs }}$ decrease with wavelength, but they are not a strong function of $\lambda$ for thinly coated BC. In addition, compared with $\mathrm{BC}$ with non-absorbing coatings, $E_{\mathrm{abs}}$ for thinly coated $\mathrm{BC}$ with absorbing coatings seems to be less wavelength dependent, while $E_{\text {abs }}$ for thickly coated BC with absorbing materials is more sensitive to wavelength.

Many studies have noticed that the lensing effect can greatly enhance the absorption of BC. However, there is also an opposite effect, which is commonly neglected. As shown in Fig. 2, as $k_{\mathrm{BrC}}$ increases, the value of $E_{\text {abs_internal }}$ of thickly coated $\mathrm{BC}$ can be below 1. This indicates that the absorption of $\mathrm{BC}$ internally mixed with $\mathrm{BrC}$ coatings may be less than the sum of the absorption of an external mixture of $\mathrm{BrC}$ coatings and $\mathrm{BC}$ when $k_{\mathrm{BrC}}$ is large. This phenomenon can be explained from physical insights. When the absorption of the coatings is weak, the light can penetrate the coatings of the $\mathrm{BC}$ materials, and the absorption of $\mathrm{BC}$ is significantly enhanced by the lensing effect. However, as the coating absorption increases, the light is blocked by the outer coatings. Therefore, the light cannot fully and deeply penetrate the absorbing coatings on $\mathrm{BC}$. As a result, the total absorption is less than the sum of the absorption of coatings and $\mathrm{BC}$ that are calculated separately. Therefore, there is a need to clas- 

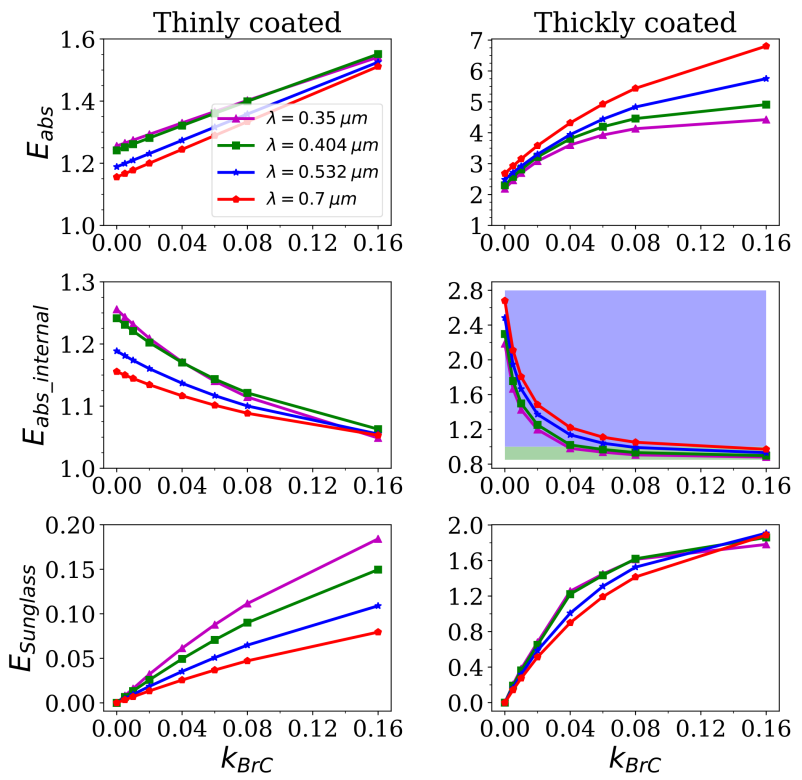

Figure 2. Effects of $k_{\mathrm{BrC}}$ on specific enhancement $\left(n_{s}=200\right)$. For thinly coated $\mathrm{BC}, D_{\mathrm{f}}=2.2$ and $f_{\mathrm{BC}}=40 \%$; for thickly coated $\mathrm{BC}, D_{\mathrm{f}}=2.6$ and $f_{\mathrm{BC}}=5 \%$. The blue shading represents the $E_{\text {abs_internal }}$ of larger than 1, while the green shading describes the range of $E_{\text {abs_internal }}$ of less than 1 .

sify the $\mathrm{BrC}$ coating effect into lensing effect ( $\left.E_{\text {abs_lensing }}\right)$ and sunglasses effect ( $E_{\text {Sunglass }}$ ), which represents the absorption enhancements and blocking effects of coatings, respectively.

Liu et al. (2017) defined the lensing effect as the absorption enhanced by the addition of non-black carbon. However, from a physical point, for $\mathrm{BC}$ with $\mathrm{BrC}$ coatings, the definition may not be clear as $\mathrm{BrC}$ also absorbs solar radiation, and it can be confused with $E_{\text {abs }}$. Therefore, here we redefine the lensing effect as the absorption enhanced by addition of non-absorbing materials. In addition, we assume that the lensing effect of $\mathrm{BC}$ with absorbing coatings is the same as those with non-absorbing coatings. Accordingly, $E_{\text {abs_lensing }}$ can be calculated using

$E_{\text {abs_lensing }}=\frac{C_{\text {abs_non-absorbing }}}{C_{\text {abs_bare }}}$,

where $C_{\text {abs_non-absorbing }}$ represents the absorption cross section of $\mathrm{BC}$ with non-absorbing coatings. The total $E_{\text {abs }}$ should be contributed to the lensing effect, absorption of $\mathrm{BrC}$ shell, and the sunglasses effect. Therefore, $E_{\mathrm{abs}}$ can be expressed by

$E_{\text {Sunglass }}=$

$$
-\frac{C_{\text {abs_coated }}-C_{\text {abs_BrC_shell }}-C_{\text {abs_non-absorbing }}}{C_{\text {abs_bare }}} .
$$

Combining Eqs. (3)-(9), we can obtain $E_{\text {Sunglass, }}$ and the negative sign represents the fact that the sunglasses effect can cause a decrease in total absorption. According to the definition of $E_{\text {Sunglass, }}$, we can easily obtain the relation that the absorption of $\mathrm{BC}$ coated with $\mathrm{BrC}$ is less than that of an external mixture of $\mathrm{BrC}$ and $\mathrm{BC}$ when $E_{\text {Sunglass }}>E_{\text {abs_lensing }}-1$.

The sensitivity of $E_{\text {Sunglass }}$ to $k_{\mathrm{BrC}}$ is shown in Fig. 2. For both thinly and thickly coated BC, $E_{\text {Sunglass }}$ increases with $k_{\mathrm{BrC}}$. Fixing $k_{\mathrm{BrC}}, E_{\text {Sunglass }}$ of thinly coated $\mathrm{BC}$ decreases with wavelength. However, for thickly coated BC, $E_{\text {Sunglass }}$ can increase with wavelength at large $k_{\mathrm{BrC}}$ values (such as $k_{\mathrm{BrC}}=0.16$ ). For the thinly coated $\mathrm{BC}$, the blocking of $E_{\text {Sunglass }}$ is less than the enhancement of $E_{\text {abs_lensing }}$ (see Figs. 5 and 10); therefore, $E_{\text {abs_internal }}$ of thinly coated $\mathrm{BC}$ is larger than 1. For thickly coated BC, the blocking of $E_{\text {Sunglass }}$ can be larger than the enhancement of $E_{\text {abs_lensing }}$ as $k_{\mathrm{BrC}}$ is larger, which leads to $E_{\mathrm{abs} \text { _internal }}$ of less than 1 . The threshold value of $k_{\mathrm{BrC}}$ is dependent on particle size and mixing states. Generally, the threshold $k_{\mathrm{BrC}}$ value decreases with particle size and coating thickness, as $E_{\text {abs_internal }}$ of $\mathrm{BC}$ thickly coated with $\mathrm{BrC}$ coatings decreases with particle size and coating thickness in the ultraviolet region (see Figs. 6 and 9).

Although the core-shell sphere model has been debated for a long time, it is still widely used in climate models. By combining the electron tomography (ET) and DDA method, Adachi et al. (2010) found that the absorption of BC with fluffy structures is significantly enhanced by a core-shell structure at $\lambda=0.55 \mu \mathrm{m}$. However, for thickly coated BC, $\mathrm{BC}$ absorption is underestimated at the UV, visible, and IR wavelengths (Kahnert et al., 2012). Mishchenko et al. (2014) have also demonstrated that the $C_{\text {abs }}$ of thickly coated BC with non-absorbing coatings is significantly underestimated by a core-shell sphere and investigated the effects of offcenter BC. Their results indicated that the $C_{\mathrm{abs}}$ values of aged $\mathrm{BC}$ covered with thick non-absorbing coatings are approximately 1.44 times higher than those calculated with a coreshell sphere model. Nevertheless, the effects of coating absorption on the applicability of the core-shell sphere model have not been evaluated. As shown in Fig. 3, $C_{\text {abs }}$ for thinly coated $\mathrm{BC}$ is enhanced by a core-shell sphere structure in the visible spectral region, which agrees with the study of Adachi et al. (2010), while it is underestimated in the ultraviolet region. In addition, the ratio of $C_{\mathrm{abs}}$ of thinly coated $\mathrm{BC}$ to the core-shell sphere model increases with $k_{\mathrm{BrC}}$. However, the applicability of the core-shell sphere model to thickly coated BC is diverse. Consistent with Kahnert et al. (2012), thickly coated $\mathrm{BC}$ absorption is underestimated by the coreshell sphere model when coated with non-absorbing materials. Nevertheless, as $k_{\mathrm{BrC}}$ increases, the underestimation becomes insignificant. The reason may be that less light can penetrate deeply into the $\mathrm{BC}$ as the $k_{\mathrm{BrC}}$ increases, which leads to less variation in absorption. Therefore, the morphological effects of BC are relatively small.

The $E_{\text {abs }}$, compared with that for the core-shell sphere model, is also calculated. For thinly coated BC, the $E_{\text {abs }}$ is significantly overestimated by the core-shell sphere model. 

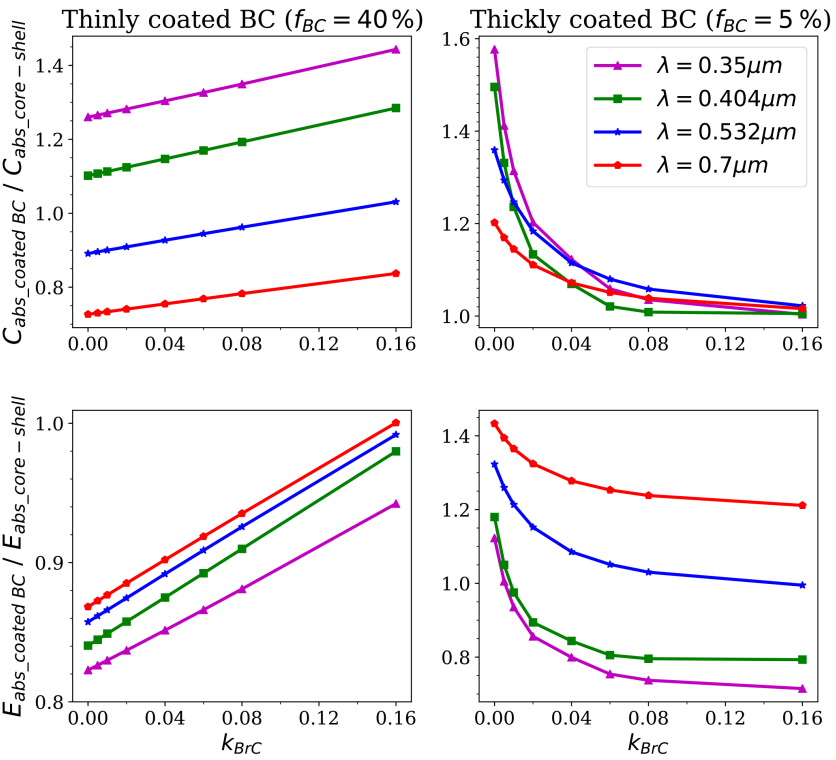

Figure 3. Effects of $k_{\mathrm{BrC}}$ on the applicability of core-shell sphere $\left(n_{s}=200\right)$.

However, this overestimation is alleviated by an increasing $k_{\mathrm{BrC}}$. For BC that is thickly coated with non-absorbing materials, the $E_{\text {abs }}$ is underestimated by the core-shell sphere model at all wavelengths, while it decreases as $k_{\mathrm{BrC}}$ becomes larger. The $E_{\text {abs }}$ can be overestimated by the coreshell sphere model in the ultraviolet spectral region when $k_{\mathrm{BrC}}$ is large. Therefore, the absorption characteristics of $\mathrm{BC}$ are significantly affected by the absorption of coatings. To agree with the measurements, typical $k_{\mathrm{BrC}}$ values are assumed according to Kirchstetter et al. (2004), as shown in Fig. S2. In this work, $k_{\mathrm{BrC}}$ values of $0.168,0.114,0.0354$ and 0.001 were assumed for 4 typical wavelengths $(\lambda=350$, 404,532 and $700 \mathrm{~nm}$, respectively) via interpolation.

\subsection{Bulk radiative properties: effects of the size distribution}

The sensitivity study conducted by Zhang et al. (2017) showed that the $E_{\text {abs }}$ for aged BC was significantly affected by the size distribution. They reported different $E_{\text {abs }}$ values of $\sim 1.7-2.4$ and $\sim 2.0-2.7$ for accumulated and coarse modes, respectively. By setting the fractal dimension to be 2.2 and $f_{\mathrm{BC}}$ to be $40 \%$, the variations in BC absorption enhancements for different particle size distributions are shown in Fig. 4. Generally, weaker absorption enhancement can be observed by increasing $\lambda$ from the ultraviolet region to the visible region, which is in agreement with the study of You et al. (2016). By defining the monomers' radii, Kahnert (2010a) demonstrated that the absorption cross section is significantly affected by the particle size, and the cubic fit can greatly describe the relations among equivalent volume radii for freshly emitted BC. However, for the absorp- tion enhancement of thinly coated $\mathrm{BC}$, the effects of size distribution are not obvious. With variations in $r_{\mathrm{g}}$ and $\sigma_{\mathrm{g}}$, the absorption enhancement changes at ranges of $\sim 1.563$ $1.603, \sim 1.427-1.465, \sim 1.2440-1.275$, and $\sim 1.146-1.169$ at $\lambda=0.35,0.404,0.532$, and $0.7 \mu \mathrm{m}$, respectively. The relative uncertainty in the absorption enhancements caused by the size distribution are $2.56 \%, 2.66 \%, 2.81 \%$, and $2.01 \%$, respectively. The effects of the size distribution on the absorption enhancement of thinly coated BC are similar at different wavelengths. Generally, $E_{\text {abs }}$ has the largest value when both $r_{\mathrm{g}}$ and $\sigma_{\mathrm{g}}$ are extremely small or extremely large.

The absorption of $\mathrm{BrC}$ and $\mathrm{BC}$ is considered separately in most cases. To investigate the difference between the absorption of internally mixed $\mathrm{BC}$ and the total absorption of $\mathrm{BrC}$ and $\mathrm{BC}$ (calculated separately), $E_{\text {abs_internal }}$ is also calculated. $E_{\text {abs_internal }}$ of thinly coated BC is greater in the visible region due to the insignificant sunglasses effects. The sensitivity of $E_{\text {abs_internal }}$ is also not obvious to the size distribution. With the size distribution varying, $E_{\text {abs_internal }}$ changes in the range of $\sim 1.055-1.099, \sim 1.081-1.112, \sim 1.132$ 1.147 , and $\sim 1.140-1.165$ for $\lambda=0.35,0.404,0.532$, and $0.7 \mu \mathrm{m}$, respectively, and the relative uncertainties are all below $2 \%$. In addition, $E_{\text {abs_lengsing shares a dependence on }}$ size distribution similar to $E_{\mathrm{abs}}$ in the visible wavelengths. The reason is that the $E_{\mathrm{abs}}$ mainly derives from lensing effects due to the weak absorption of coatings. However, for ultraviolet wavelengths, there is a completely different pattern due to the sunglasses effect.

As both the lensing effect and sunglasses effect may affect the $E_{\text {abs_internal }}, E_{\text {abs_lensing }}$ and $E_{\text {Sunglass }}$ are also investigated, and the results are shown in Fig. 5. Here $E_{\text {abs_lensing }}$ 1 represents the $E_{\text {abs }}$ enhancement caused by the lensing effect, and $E_{\text {Sunglass }}$ is the $E_{\text {abs }}$ decrease caused by the sunglasses effect. For thinly coated BC, although both $E_{\text {abs_lensing }}$ and $E_{\text {Sunglass }}$ decrease with increasing $\lambda$, compared with $E_{\text {Sunglass }}, E_{\text {abs_lensing }}$ has less spectral dependence. $E_{\text {abs_lensing }}-1$ is in the range of $\sim 0.205-0.283, \sim$ $0.186-0.251, \sim 0.163-0.2$, and $\sim 0.147-0.171$ for $\lambda=0.35$, $0.404,0.532$, and $0.7 \mu \mathrm{m}$, respectively. However, $E_{\text {Sunglass }}$ can reach approximately 0.2 at $\lambda=0.35 \mu \mathrm{m}$, but is about 0 at $\lambda=0.7 \mu \mathrm{m}$. In addition, for thinly coated BC, the enhancements of the lensing effect are stronger than the blocking of the sunglasses effect. Therefore, $E_{\text {abs internal is above } 1 \text { for }}$ thinly coated BC (as shown in Figs. 2 and 4).

Figure 6 illustrates the effects of size distribution on $E_{\text {abs }}$ and $E_{\text {abs_internal }}$ of thickly coated BC. Compared with thinly coated BC, there is a different effect pattern for thickly coated BC. For ultraviolet wavelengths (e.g., $\lambda=0.35$ and $0.404 \mu \mathrm{m})$, absorption enhancements decrease as $r_{\mathrm{g}}$ or $\sigma_{\mathrm{g}}$ increases. This indicates that as the particle becomes larger or the size distribution becomes wider, the absorption enhancements become weaker. However, for the visible wavelengths, the effects of the size distribution are quite complicated. The absorption enhancements are relatively small when both $r_{\mathrm{g}}$ and $\sigma_{\mathrm{g}}$ are extremely large or small. The peak value com- 

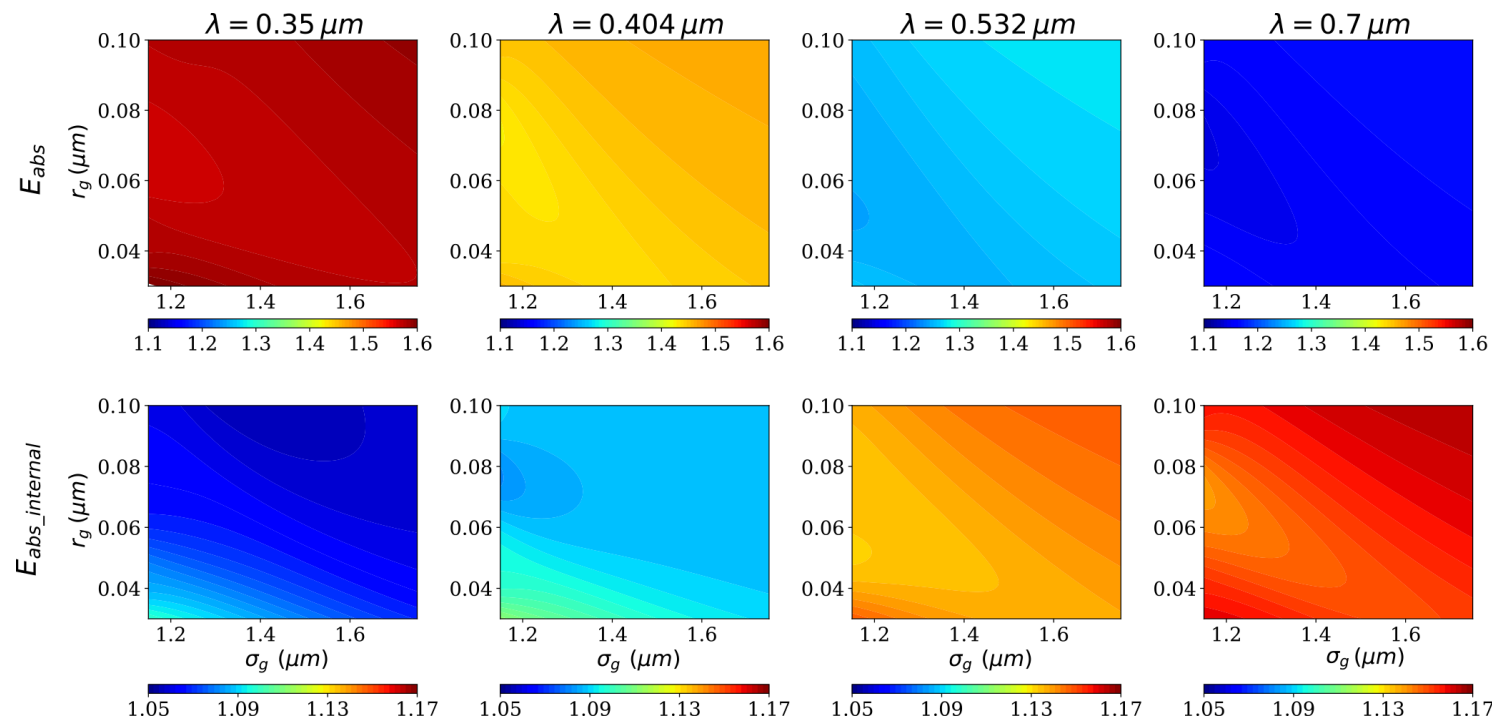

Figure 4. $E_{\mathrm{abs}}$ and $E_{\mathrm{abs} \_ \text {internal }}$ of thinly coated $\mathrm{BC}$ with $\mathrm{BrC}$ coatings at different size distributions $\left(D_{\mathrm{f}}=2.2, f_{\mathrm{BC}}=40 \%\right)$.
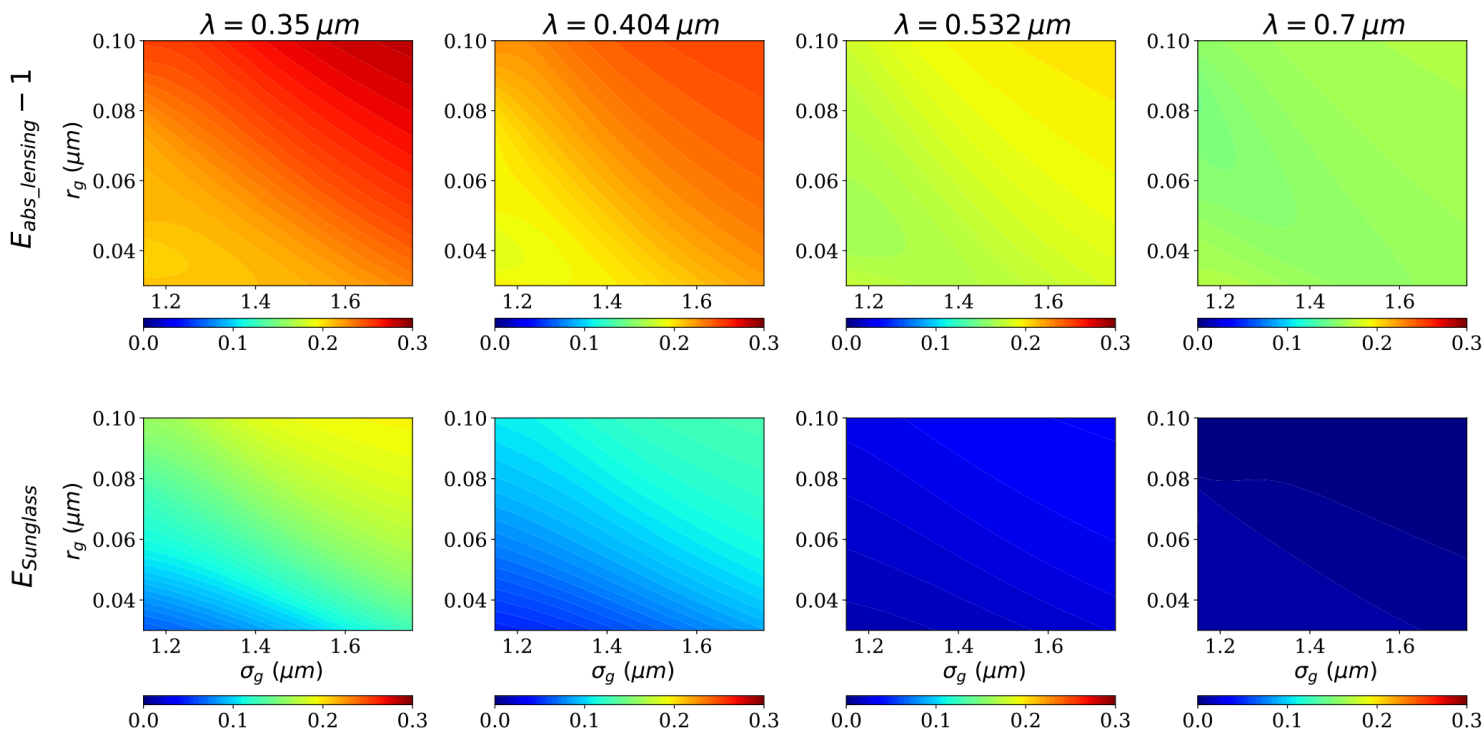

Figure 5. Similar to Fig. 4, but for $E_{\text {abs_lensing }}$ and $E_{\text {Sunglass }}$.

monly occurs when $\sigma_{\mathrm{g}}$ is extremely small. Zhang et al. (2017) concluded that the $E_{\text {abs }}$ of aged $\mathrm{BC}$ is more sensitive to the size distribution in the accumulation mode (in which $\sigma_{\mathrm{g}}$ is relatively small), while the $E_{\text {abs }}$ of coarsely coated BC aggregates (i.e., with large $\sigma_{\mathrm{g}}$ ) show little variation with $r_{\mathrm{g}}$. This is precisely true for $\mathrm{BC}$ with weak absorbing coatings, as shown in the results for $\lambda=0.7 \mu \mathrm{m}$. However, for BC with absorbing coatings, $E_{\text {abs }}$ is sensitive to the size distribution for both modes. When fixing the $f_{\mathrm{BC}}$ to be $6 \%$, as $r_{\mathrm{g}}$ and $\sigma_{\mathrm{g}}$ vary, the absorption enhancements change in the ranges of $\sim 3.7-7.1, \sim 3.85-5.80, \sim 3.06-3.74$, and $\sim 1.63-2.59$ for $\lambda=0.35,0.404,0.532$, and $0.7 \mu \mathrm{m}$, respectively, and the un- certainties in $E_{\text {abs }}$ can reach up to $91.9 \%, 50.7 \%, 22.2 \%$, and $60.7 \%$, respectively.

$E_{\text {abs_internal }}$ of thickly coated $\mathrm{BC}$ is also significantly affected by the size distribution. With the $r_{\mathrm{g}}$ varying in the range of $0.03-0.1 \mu \mathrm{m}$ and $\sigma_{\mathrm{g}}$ varying in the range of 1.15 $1.75, E_{\text {abs_internal varies in the range of } 0.871-1.053,0.891-}$ $1.121,1.115-1.383$, and $1.615-2.442$ for $\lambda=0.35,0.404$, 0.532 , and $0.7 \mu \mathrm{m}$, respectively. In addition, effects of the size distribution on $E_{\text {abs_internal }}$ and $E_{\text {abs }}$ are related to wavelength. $E_{\text {abs_internal decreases with particle size (i.e, increas- }}$ ing $r_{\mathrm{g}}$ ) at ultraviolet wavelengths, while it increases as the particles become larger at visible wavelengths (also see Fig. S6). Based on physical insights, the reason may be due to 

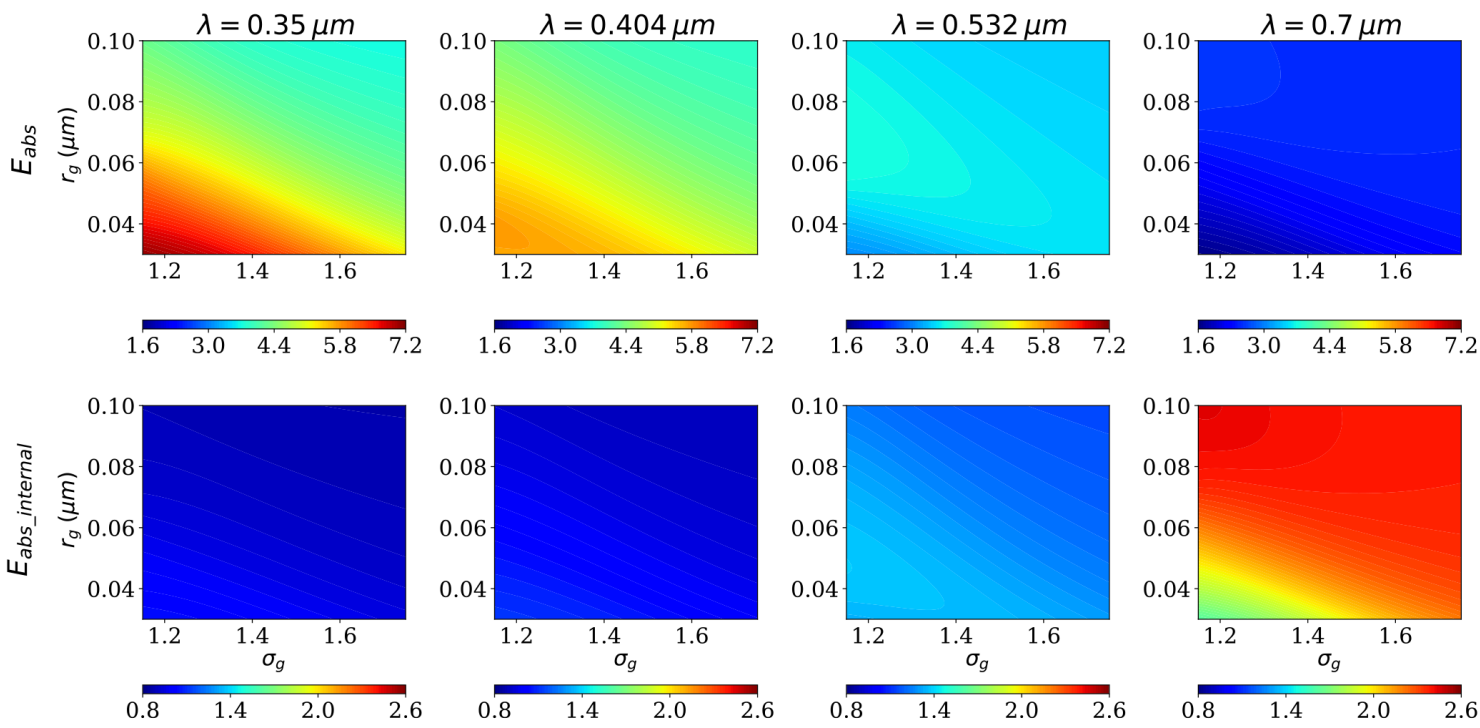

Figure 6. $E_{\mathrm{abs}}$ and $E_{\mathrm{abs} \_ \text {internal }}$ of $\mathrm{BC}$ thickly coated with $\mathrm{BrC}$ at different size distributions $\left(D_{\mathrm{f}}=2.6, f_{\mathrm{BC}}=6 \%\right)$.
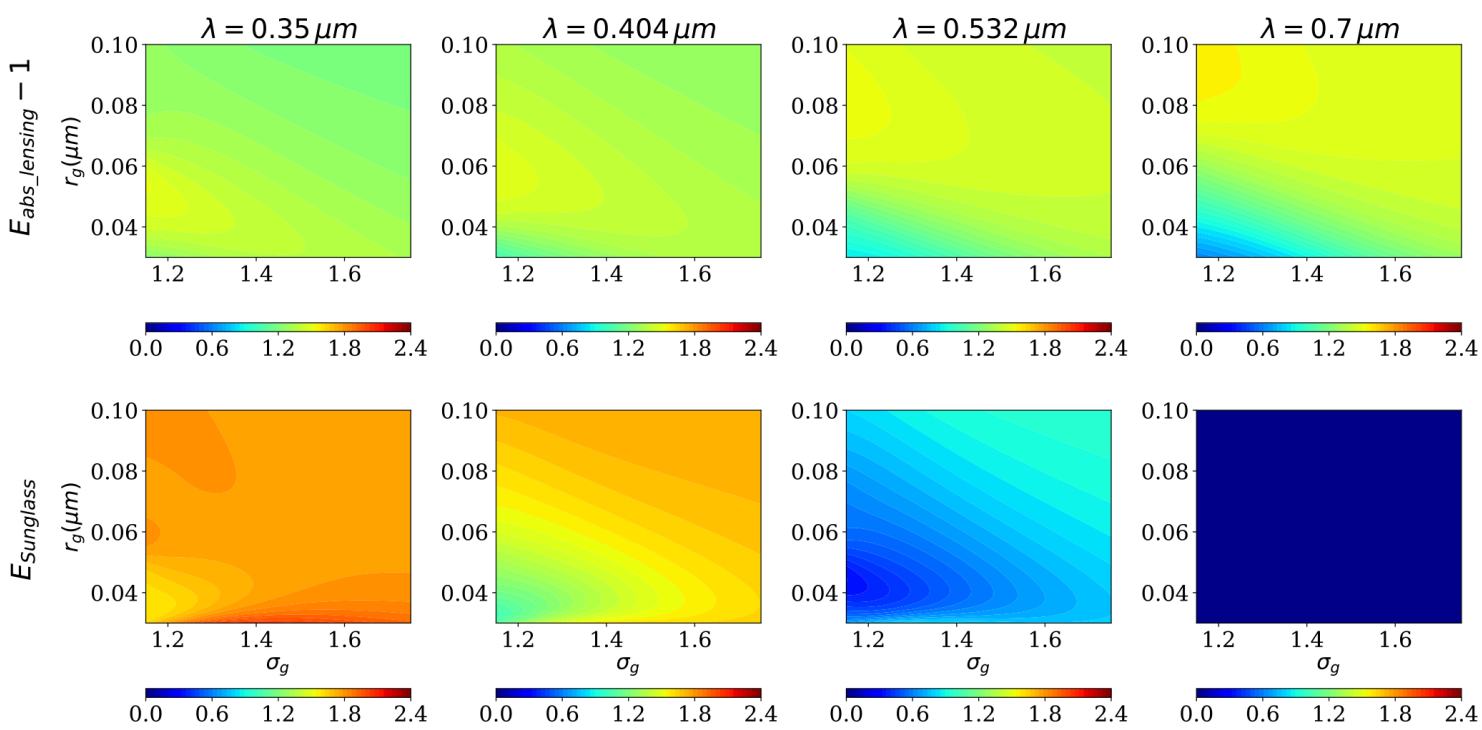

Figure 7. Similar to Fig. 6, but for $E_{\text {abs_lensing }}$ and $E_{\text {Sunglass }}$.

two aspects. When the wavelength is in the ultraviolet region, the absorption of the coatings is large; therefore, the blocking effects of the coatings are obvious. Given identical $f_{\mathrm{BC}}$ values, the superficial area of the outer coating becomes lager as the particle size increases. As a result, the blocking effects of the outer coatings increase. Therefore, the $E_{\text {abs_internal }}$ decreases. At visible wavelengths, the absorption of the coatings is negligible, and the light can penetrate deeply into BC. At that point, the main factor is the enhancement of the lensing effect, and the larger particles may cause a larger superficial area, which leads to the enhanced $E_{\text {abs_internal. }} E_{\text {abs }}$ shares similar dependences on the size distribution for different wavelengths. In addition, $E_{\text {abs_internal }}$ can be less than 1 .
This means that the enhancement of the lensing effect is less than the blocking of the sunglasses effect. In climate models, the $\sigma_{\mathrm{g}}$ is commonly assumed to be a fixed value, and the $\mathrm{BC}$ size distribution is commonly assumed to be in accumulation mode (Liu et al., 2012). The effects of the size distribution at fixed $\sigma_{\mathrm{g}}=1.5$ are supplemented in Figs. S4-S7.

The effects of the size distribution on the lensing effect and sunglasses effect of thickly coated BC are shown in Fig. 7. $E_{\text {abs_lensing }}$ is in the range of 2.197-2.514, 2.045$2.486,1.844-2.526$, and $1.6147-2.568$ at $\lambda=0.35,0.404$, 0.532 , and $0.7 \mu \mathrm{m}$, respectively. It seems that $E_{\text {abs_lensing }}$ is more sensitive to the size distribution in the visible region compared with the ultraviolet region. However, $E_{\text {abs_lensing }}$ 
at different wavelengths does not deviate largely, and the uncertainty is within $25 \%$. However, effects of the size distribution on $E_{\text {Sunglass }}$ largely depend on the wavelength. Fixing $f_{\mathrm{BC}}=6 \%, E_{\text {Sunglass }}$ is in the range between 1.586 and 2.062 at $\lambda=0.35 \mu \mathrm{m}$ and in the range between 0.001 and 0.027 at $\lambda=0.7 \mu \mathrm{m}$. In addition, from Fig. 7 , we can also see that the enhancement of the lensing effect (represented by $\left.E_{\text {abs_lensing }}-1\right)$ is less than the blocking of the sunglasses effect in the ultraviolet region for thickly coated $\mathrm{BC}$, while the opposite phenomenon is observed in the visible region.

\subsection{Bulk radiative properties: effects of the composition ratio}

To make our calculation meaningful, we compare the calculated $E_{\text {abs }}$ and mass absorption cross section (MAC) with the measurements of Liu et al. (2015b). The measurement results for $E_{\text {abs }}$ and MAC are estimated from Fig. 1 and supplementary Fig. 2 of Liu et al. (2015b). MAC is calculated using

$\mathrm{MAC}=C_{\mathrm{abs} \_ \text {coated }} / m_{\mathrm{BC}}$,

$m_{\mathrm{BC}}=\int_{r_{\min }}^{r_{\max }} \rho_{\mathrm{BC}} \frac{4}{3} \pi r^{3} n(r) \mathrm{d} r$,

where $m_{\mathrm{BC}}$ and $\rho_{\mathrm{BC}}$ represent the mass and mass density of $\mathrm{BC}$, respectively. To agree with measurements, the coating thickness is determined by the mass ratio of $\mathrm{BrC}$ and $\mathrm{BC}$ components $M_{\mathrm{R}}$. In this study, $M_{\mathrm{R}}$ is calculated by:

$M_{\mathrm{R}}=\rho_{\mathrm{BrC}} \cdot\left(1-f_{\mathrm{BC}}\right) /\left(\rho_{\mathrm{BC}} \cdot f_{\mathrm{BC}}\right)$,

where $\rho_{\mathrm{BrC}}$ represents the mass density of $\mathrm{BrC}$. In this work, we assume ambient $\mathrm{BC}$ mainly composed of primary organic matter with a low degree of oxidation. Based on the study of Nakao et al. (2013), an OC mass density range of $1-1.2 \mathrm{~g} \mathrm{~cm}^{-3}$ has been used by Liu et al. (2017). $\rho_{\mathrm{BrC}}=1.1 \mathrm{~g} \mathrm{~cm}^{-3}$ is assumed in this work. For the BC mass density, the study of Horvath (1993) gives values of $\rho_{\mathrm{BC}}=0.625 \mathrm{~g} \mathrm{~cm}^{-3}$ and $\rho_{\mathrm{BC}}=1.125 \mathrm{~g} \mathrm{~cm}^{-3}$. However, Fuller et al. (1999a) pointed out that the values may not be representative for $\mathrm{BC}$ in the atmosphere. Medalia and Richards (1972) and Janzen (1980) suggested $\rho_{\mathrm{BC}}$ in the range of 1.8-1.9 $\mathrm{g} \mathrm{cm}^{-3}$, while Bergstrom (1972) found the $\rho_{\mathrm{BC}}$ value of $1.9-2.1 \mathrm{~g} \mathrm{~cm}^{-3}$. Bond and Bergstrom (2006) suggested using a value of $1.8 \mathrm{~g} \mathrm{~cm}^{-3}$. Figure $\mathrm{S} 8$ compares the computations with measurements by assuming $\rho_{\mathrm{BC}}=$ $1.8 \mathrm{~g} \mathrm{~cm}^{-3}$. We assume that $E_{\mathrm{abs}}$ and MAC at $\lambda=0.7 \mu \mathrm{m}$ do not deviate largely with those at $\lambda=0.781 \mu \mathrm{m}$. Modeled $E_{\text {abs }}$ at $\lambda=0.7 \mu \mathrm{m}$ agrees well with the measurements. Although $E_{\text {abs }}$ at $\lambda=0.404 \mu \mathrm{m}$ seems to be relatively higher than the measurements, it does not deviate largely from the measurements. However, modeled MAC is a little smaller than the measured MAC. Similar results were obtained for bare BC (Kahnert, 2010b; Liu and Mishchenko, 2005). Therefore, $\rho_{\mathrm{BC}}=1.8 \mathrm{~g} \mathrm{~cm}^{-3}$ may be a little high for estimation of MAC.
Table 2. MAC $\left(\mathrm{m}^{2} \mathrm{~g}^{-1}\right)$ for bare BC at different $D_{\mathrm{f}}$ values $\left(r_{\mathrm{g}}=\right.$ $\left.0.06 \mu \mathrm{m}, \sigma_{\mathrm{g}}=1.5\right)$.

\begin{tabular}{lccc}
\hline$\lambda(\mathrm{nm})$ & $D_{\mathrm{f}}=1.8$ & $D_{\mathrm{f}}=2.2$ & $D_{\mathrm{f}}=2.6$ \\
\hline 350 & 9.30 & 9.03 & 8.48 \\
404 & 8.14 & 7.95 & 7.60 \\
532 & 6.20 & 6.11 & 6.02 \\
700 & 4.68 & 4.64 & 4.65 \\
\hline
\end{tabular}

Bond and Bergstrom (2006) concluded that the MAC value of $7.5 \pm 1.2 \mathrm{~m}^{2} \mathrm{~g}^{-1}$ for bare $\mathrm{BC}$ can be assumed at $\lambda=0.55 \mu \mathrm{m}$ by reviewing 21 publications of MAC measurements. However, our calculated MAC of $6.02-6.2 \mathrm{~m}^{2} \mathrm{~g}^{-1}$ (see Table 2) at $\lambda=0.532 \mu \mathrm{m}$ lies below the range of MAC values suggested by Bond and Bergstrom (2006). Similar conclusions were drawn by Kahnert (2010b) and Liu and Mishchenko (2005). However, our calculated MAC agrees well with the calculated MAC of $6.0 \pm 0.1 \mathrm{~m}^{2} \mathrm{~g}^{-1}$ by Kahnert (2010b) at $\lambda=0.55 \mu \mathrm{m}$. As MAC depends significantly on BC mass density, to agree with measurements, Liu and Mishchenko (2005) used $\rho_{\mathrm{BC}}=1.0 \mathrm{~g} \mathrm{~cm}^{-3}$. However, as pointed by Kahnert (2010b), the measured MAC and modeled MAC were not at the same wavelength, therefore leading to too low retrieved $\rho_{\mathrm{BC}}$. To raise the computed MAC values to the average observed value of $\mathrm{MAC}=(7.5 \pm$ 1.2) $\mathrm{m}^{2} \mathrm{~g}^{-1}, \rho_{\mathrm{BC}}=1.3-1.4 \mathrm{~g} \mathrm{~cm}^{-3}$ was suggested by Kahnert (2010b). However, this $\rho_{\mathrm{BC}}$ value is rather drastically smaller than the value suggested by Bond and Bergstrom (2006). Therefore, Kahnert (2010b) suggested assuming $\rho_{\mathrm{BC}}=1.5-1.7 \mathrm{~g} \mathrm{~cm}^{-3}$ to raise the computational MAC results to the lower bound of the observations. By assuming $\rho_{\mathrm{BC}}=1.5 \mathrm{~g} \mathrm{~cm}^{-3}$, the comparison of modeled MAC and $E_{\text {abs }}$ with measurements is shown in Fig. S9. Overall, the modeled MAC and $E_{\text {abs }}$ agree relatively well with the measurement by assuming $\rho_{\mathrm{BC}}=1.5 \mathrm{~g} \mathrm{~cm}^{-3}$. Therefore, $\rho_{\mathrm{BC}}=$ $1.5 \mathrm{~g} \mathrm{~cm}^{-3}$ is assumed in this study. In addition, according to the previous studies (Liu et al., 2015a; Zhang et al., 2016), the shell / core ratio $D_{\mathrm{p}} / D_{\mathrm{c}}$ (equivalent particle diameter divided by $\mathrm{BC}$ core diameter) was observed to be commonly in the range of 1.1-2.7, and the corresponding $M_{\mathrm{R}}$ is approximately $0.24-13.9$. Therefore, $M_{\mathrm{R}}$ of $0-13.9$ is considered in this work.

Figure 8 compares the $E_{\text {abs }}$ and $E_{\text {abs_internal for thinly }}$ coated $\mathrm{BC}$ with different fractal dimensions at different composition ratios. Following Liu et al. (2018), a $r_{\mathrm{g}}$ of $0.06 \mu \mathrm{m}$ and a $\sigma$ of 1.5 are assumed to reflect the real size distribution of BC. It is expected that as the coatings increase, $E_{\mathrm{abs}}$ becomes much stronger. With $M_{\mathrm{R}}$ varying from 0 to $2.93, E_{\mathrm{abs}}$ variations of $\sim 1-2.5, \sim 1-2.2, \sim 1-1.6$, and $\sim 1-1.285$ are obtained for $\lambda=0.35,0.404,0.532$, and $0.7 \mu \mathrm{m}$, respectively. The $E_{\text {abs }}$ for thinly coated BC with weakly absorbing materials (i.e., $\lambda=0.7 \mu \mathrm{m}$ ) is significantly lower than that for the core-shell sphere, as reported by Zhang et al. (2017), where 

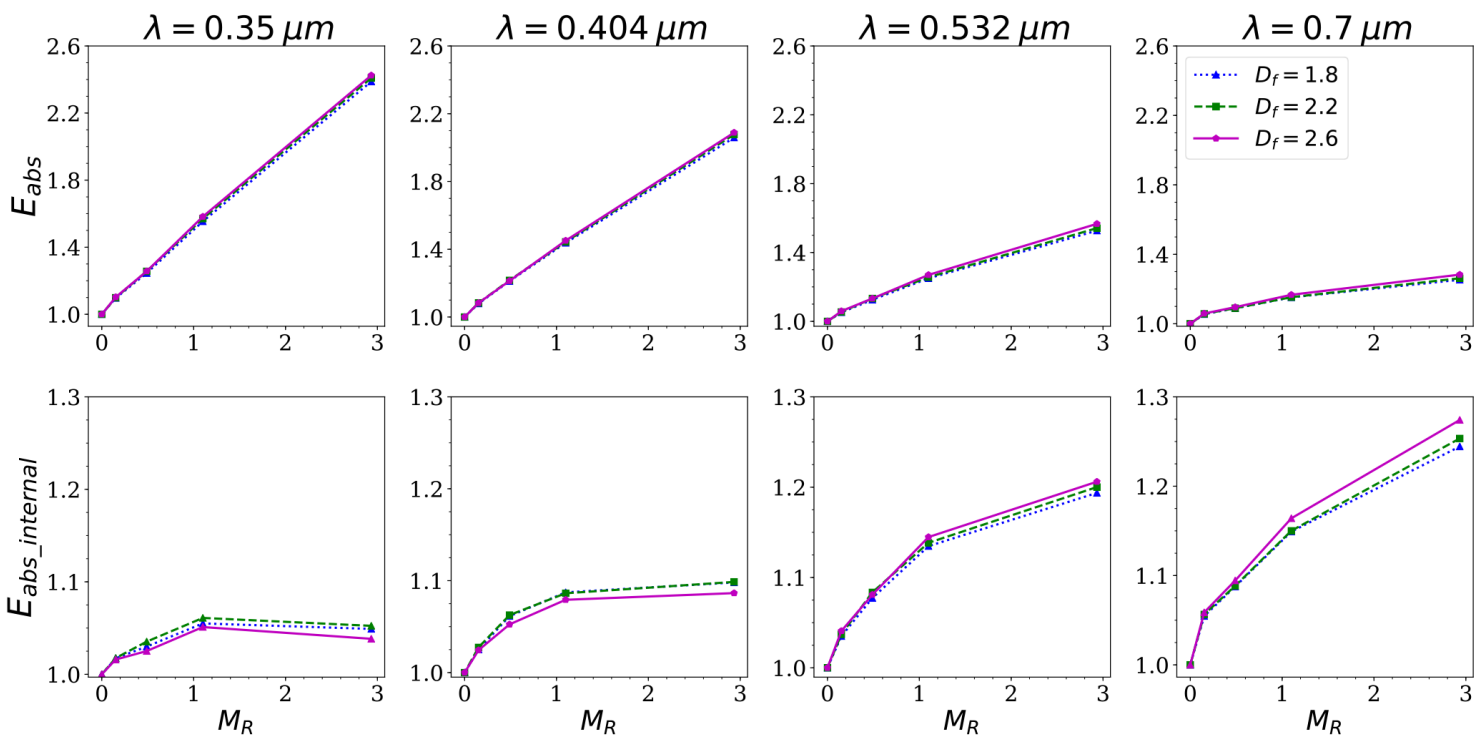

Figure 8. $E_{\mathrm{abs}}$ and $E_{\mathrm{abs} \_ \text {internal }}$ of thinly coated $\mathrm{BC}$ with $\mathrm{BrC}$ coatings varying with $M_{\mathrm{R}}$ for different $D_{\mathrm{f}}$ values $\left(r_{\mathrm{g}}=0.06 \mu \mathrm{m}, \sigma_{\mathrm{g}}=1.5\right)$.

$E_{\text {abs }}$ can reach approximately 1.5 when the shell / core ratio is $1.6\left(M_{\mathrm{R}}=2.2709\right)$ at $\lambda=0.55 \mu \mathrm{m}$. Even though the results are gained at two different wavelengths, the $E_{\text {abs }}$ for $\mathrm{BC}$ that is coated with weakly absorbing coatings should not deviate substantially between $\lambda=0.55 \mu \mathrm{m}$ and $\lambda=0.7 \mu \mathrm{m}$ (see Fig. 12). Therefore, the differences from the previous study are mainly caused by the BC shape, as demonstrated in Fig. 3. When the relative contents of BC vary, substantial variations in $E_{\text {abs_internal }}$ can also be observed. As $M_{\mathrm{R}}$ varies in the range of $0-2.93, E_{\text {abs_internal }}$ increases from 1 to $1.07,1$ to $1.1,1$ to 1.22 , and 1 to 1.285 for $\lambda=0.35,0.404$, 0.532 , and $0.7 \mu \mathrm{m}$, respectively. $E_{\text {abs_internal }}$ of thinly coated BC increases with $M_{\mathrm{R}}$ in the visible spectral region, while a little decrease in $E_{\text {abs_internal }}$ can be observed in the ultraviolet region as $M_{\mathrm{R}}$ increases when $M_{\mathrm{R}}$ is larger than a threshold value. This is mainly caused by the blocking of the sunglasses effect.

At different wavelengths, the effects of $D_{\mathrm{f}}$ may vary. $E_{\text {abs_internal }}$ increases with $D_{\mathrm{f}}$ in the visible wavelengths, as the more compact structure can lead to a greater lensing interaction. While in the ultraviolet region, as the structure becomes more compact, the interaction of absorbing coatings also increases; therefore, the blocking effects of outer coatings are greater. Therefore, the $E_{\text {abs_internal }}$ can decrease with $D_{\mathrm{f}}$ when $D_{\mathrm{f}}$ is greater than a threshold value. Even though Cheng et al. (2014) and Luo et al. (2018b) showed that the effects of $D_{\mathrm{f}}$ on $C_{\text {abs }}$ are not obvious for thinly coated BC, for $E_{\text {abs }}$ of thinly coated BC, the sensitivity of $D_{\mathrm{f}}$ has not been investigated. To quantify the effects of $D_{\mathrm{f}}$, the relative deviations between $D_{\mathrm{f}}=1.8$ and $D_{\mathrm{f}}=2.6$ are also calculated for thinly coated BC. From Fig. 8, we found that the differences in $E_{\text {abs }}$ and $E_{\text {abs_internal }}$ among different values of $D_{\mathrm{f}}$ are larger for thicker coatings. Therefore, to evalu- ate the maximum uncertainty, the $f_{\mathrm{BC}}$ is fixed to be $20 \%$. As shown in Fig. 9, the differences in $E_{\text {abs }}$ and $E_{\text {abs_internal }}$ between $D_{\mathrm{f}}=1.8$ and $D_{\mathrm{f}}=2.6$ are all below $5 \%$. $E_{\text {abs }}$ of $\mathrm{BC}$ thinly coated with non-absorbing coatings is more obviously affected by $D_{\mathrm{f}}$. However, the relative deviations between $D_{\mathrm{f}}=1.8$ and $D_{\mathrm{f}}=2.6$ do not exceed $12 \%$ (as shown in Fig. S10.).

To reveal the factors that contribute to the complex $E_{\text {abs_internal }}$, the effects of $M_{\mathrm{R}}$ on $E_{\text {abs_lensing }}$ and $E_{\text {Sunglass }}$ of thinly coated $\mathrm{BC}$ are investigated at different wavelengths.

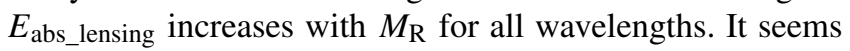
that the sensitivity of $E_{\text {abs_lensing }}$ to $M_{\mathrm{R}}$ is more obvious in the ultraviolet region compared with the visible region. Fixing $D_{\mathrm{f}}=2.2$, with $M_{\mathrm{R}}$ varying from 0 to $2.93, E_{\text {abs_lensing }}$ increases from 1 to $1.46,1.4,1.32$, and 1.25 for $\lambda=0.35,0.404$, 0.532 , and $0.7 \mu \mathrm{m}$, respectively. In addition, more compact structure can result in stronger lensing interaction among monomers and thus leads to an $E_{\text {abs_lensing }}$ increase with $D_{\mathrm{f}}$. Moreover, compared with the visible region, the effects of $D_{\mathrm{f}}$ are more obvious at the ultraviolet region. $E_{\text {Sunglass }}$ also increases with $D_{\mathrm{f}}$, as a more compact structure may lead to stronger blocking interaction among BC monomers. As expected, $E_{\text {Sunglass }}$ is stronger in the ultraviolet region, while it tends to be 0 in the visible region. As $M_{\mathrm{R}}$ reaches 2.93, $E_{\text {Sunglass }}$ can reach approximately 0.46 at $\lambda=0.35 \mu \mathrm{m}$, while $E_{\text {Sunglass }}$ is below 0.02 at $\lambda=0.7 \mu \mathrm{m}$.

Figure 11 demonstrates the absorption enhancements of thickly coated BC at different wavelengths for different composition ratios. Similar to thinly coated BC, $E_{\text {abs }}$ increases with increasing $M_{\mathrm{R}}$ or decreasing $\lambda$. When setting $r_{\mathrm{g}}=$ $0.06 \mu \mathrm{m}$ and $\sigma_{\mathrm{g}}=1.5$, as $M_{\mathrm{R}}$ varies from 6.6 to $13.9, E_{\mathrm{abs}}$ increases from 3.4 to 5.4 and 3.25 to 5.2 for $\lambda=0.35$ and $\lambda=0.404 \mu \mathrm{m}$, respectively, while $E_{\mathrm{abs}}$ varies from 2.78 to 

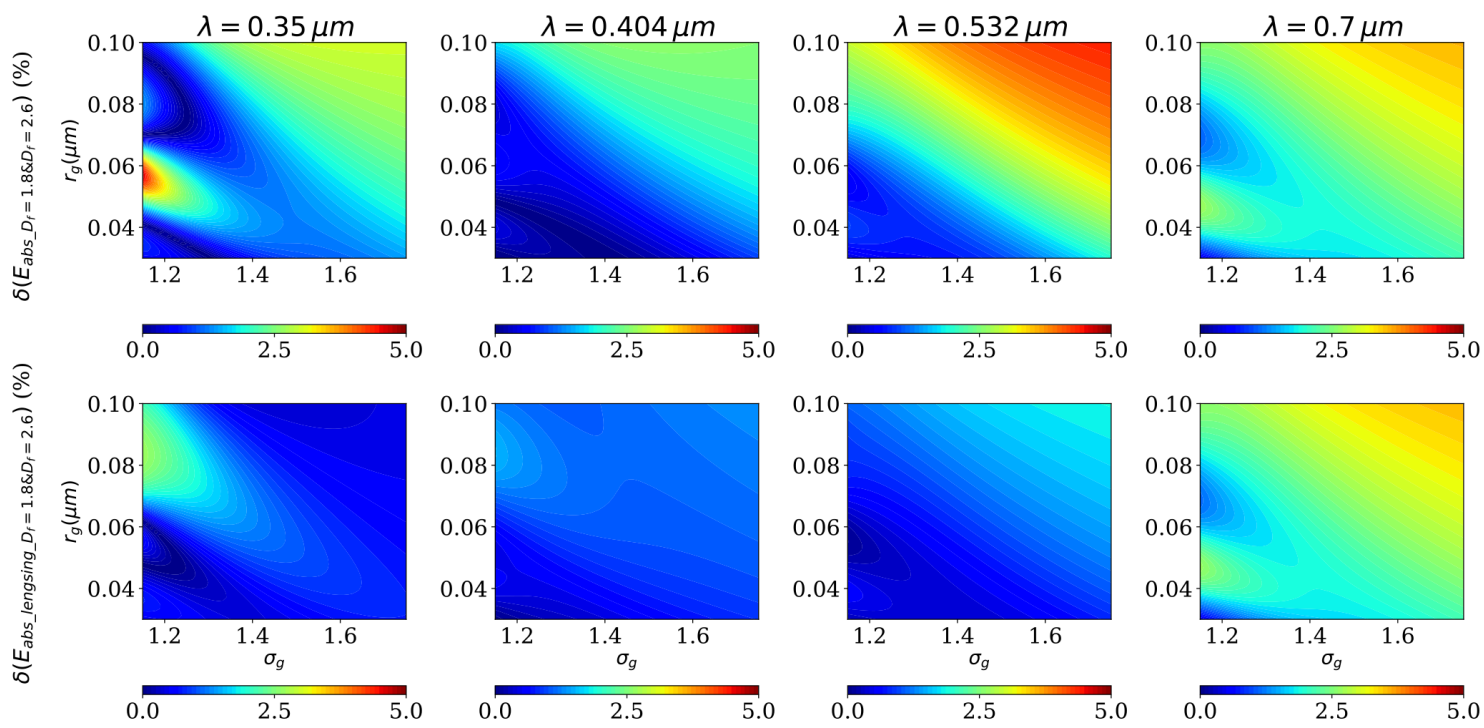

Figure 9. The relative deviations of absorption properties between $D_{\mathrm{f}}=1.8$ and $D_{\mathrm{f}}=2.6$ for thinly coated $\mathrm{BC}$ with $\mathrm{BrC}$ coating $\left(f_{\mathrm{BC}}=\right.$ $20 \%)$.
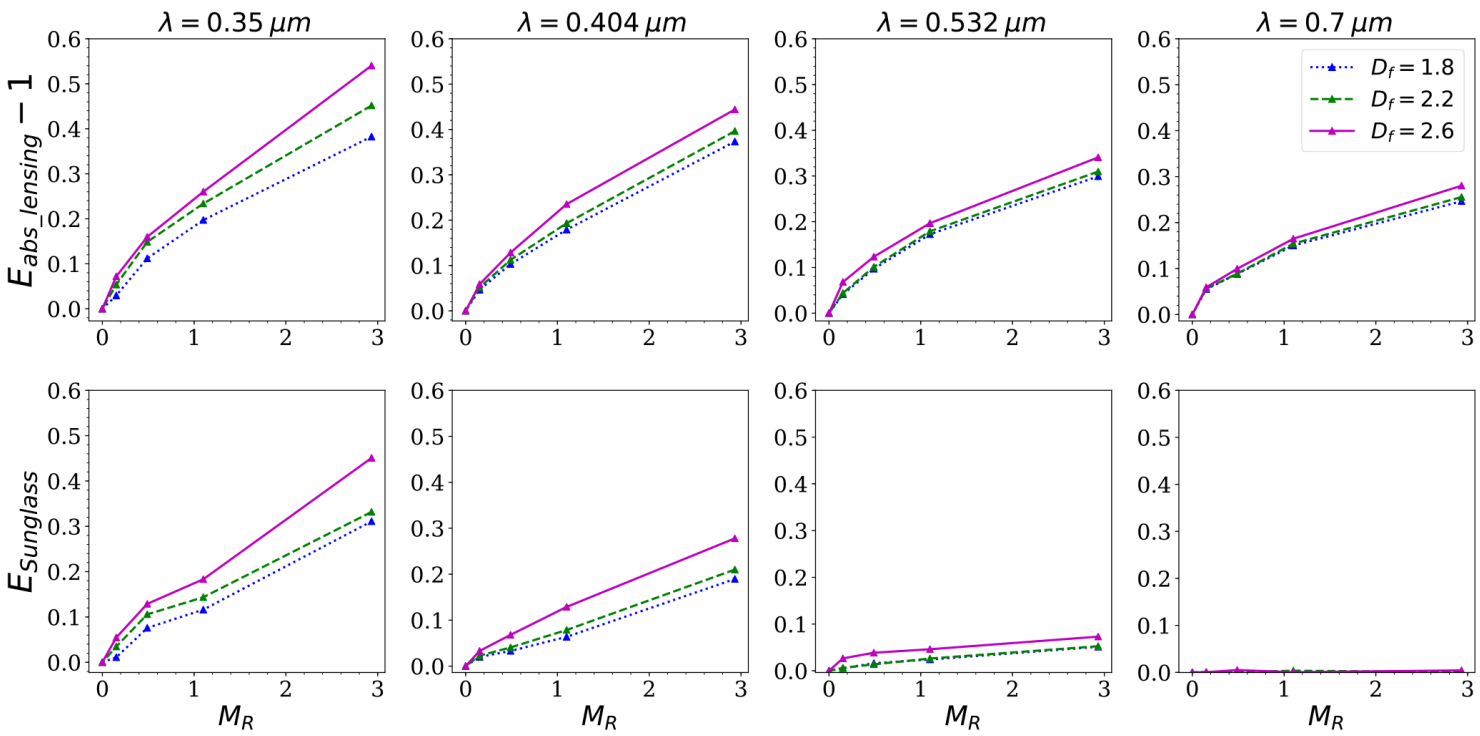

Figure 10. Similar to Fig. 8, but for $E_{\text {abs_lensing }}$ and $E_{\text {Sunglass. }}$.

3.96 and 2.2 to 2.4 for $\lambda=0.532$ and $0.7 \mu \mathrm{m}$, respectively. In addition, the $E_{\text {abs }}$ seems to be more sensitive to the composition ratios in the ultraviolet wavelengths. This may be caused by the absorption of coatings, which can substantially enhance the total absorption. In addition, the combined $E_{\text {abs }}$ values of thinly coated and thickly coated $\mathrm{BC}$ range for $\mathrm{BC}$ with $\mathrm{BrC}$ coatings is much wider than that for $\mathrm{BC}$ with nonabsorbing coatings ( $E_{\text {abs }}$ of $\sim 1-2.4$ ) (Zhang et al., 2017, 2018).

At visible wavelengths, the $E_{\text {abs_internal }}$ is greater than 1 due to the small blocking effects of BrC. Defining $r_{\mathrm{g}}$ to be $0.06 \mu \mathrm{m}$ and $\sigma_{\mathrm{g}}$ to be 1.5 , as $M_{\mathrm{R}}$ varies from 6.6 to 13.9,
$E_{\text {abs_lensing }}$ ranges from $\sim 1.222$ to 1.337 and $\sim 2.115$ to 2.357 for $\lambda=0.532$ and $0.7 \mu \mathrm{m}$, respectively. This indicates that the total absorption of $\mathrm{BC}$ and $\mathrm{BrC}$ can be substantially enhanced by the lensing effects. However, for ultraviolet wavelengths, the $E_{\text {abs_internal }}$ is less than $1 . E_{\text {abs_internal }}$ is within $\sim 0.913-0.924$ and $\sim 0.956-0.974$ for $\lambda=0.35$ and $\lambda=0.404 \mu \mathrm{m}$, respectively. This demonstrates the absorbing coatings can significantly block the light into BC. Therefore, the total absorption is less than the sum of $\mathrm{BrC}$ absorption and $\mathrm{BC}$ absorption. In recent studies, the enhancements of lensing effects has gained increasing attention. However, few studies have investigated the blocking effects of absorbing 

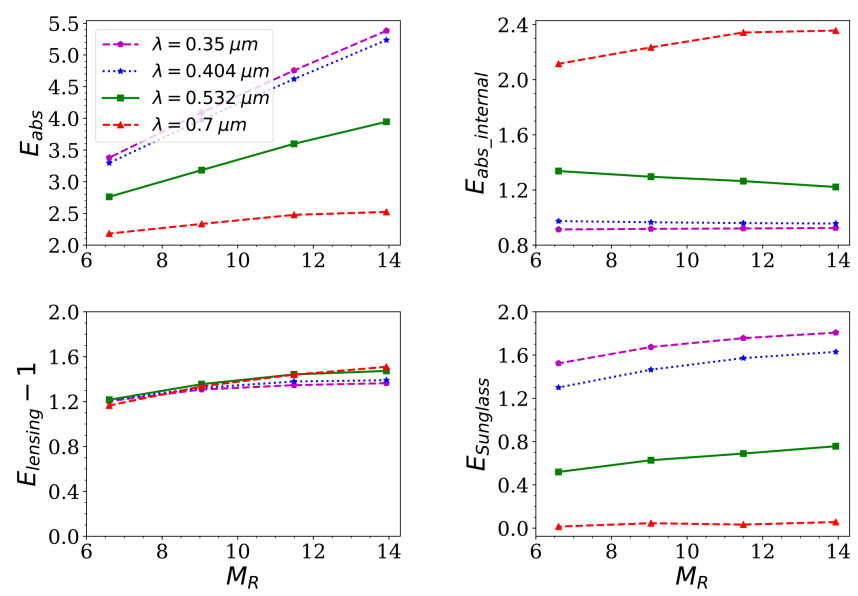

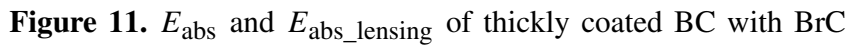
coatings varying with $M_{\mathrm{R}}\left(r_{\mathrm{g}}=0.06 \mu \mathrm{m}, \sigma_{\mathrm{g}}=1.5\right)$.

coatings. As a matter of fact, the blocking effect of absorbing coatings is also a significant factor that affects the to-

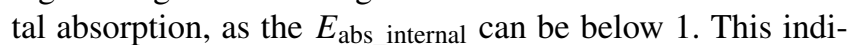
cates that the blocking effects of absorbing coatings may be greater than the enhancements of the lensing effects. Therefore, when $\mathrm{BC}$ is coated with $\mathrm{BrC}$, we should not only focus on the enhancements of the lensing effects but also carefully consider the blocking effects of the coatings.

There is a different dependence on $M_{\mathrm{R}}$ for $E_{\text {abs_internal }}$ at different wavelengths. $E_{\text {abs_internal }}$ increases with $M_{\mathrm{R}}$ at relatively long wavelengths (eg. $\lambda=0.7 \mu \mathrm{m}$ ), while decreases as the coatings become thicker at relatively short wavelengths $(0.404$ and $0.532 \mu \mathrm{m})$. This phenomenon can also be explained from physical insights. When the wavelength is short, increased thickness of the coatings may lead to a greater sunglasses effect, which weakens the total absorption of the coatings and BC. However, at $\lambda=0.7 \mu \mathrm{m}$, enhanced $E_{\text {abs_internal }}$ can be obtained by increasing the coatings due to the negligible blocking effects of the coatings. In addition, $E_{\text {abs_internal }}$ increases with wavelength due to the decrease in coating absorption (see Fig. 2). $E_{\text {abs_internal of }}$ thickly coated BC is insensitive to $M_{\mathrm{R}}$ at $\lambda=0.35 \mu \mathrm{m}$ due to the similar variations in $E_{\text {abs_lensing }}$ and $E_{\text {Sunglass }}$ with $M_{\mathrm{R}}$. As $M_{\mathrm{R}}$ varies from 6.6 to $13.9, E_{\text {abs lesnig increases from }}$ 2.204 to $2.363,2.214$ to $2.390,2.216$ to 2.473 , and 2.165 to 2.509 at $\lambda=0.35,0.404,0.532$, and $0.7 \mu \mathrm{m}$, respectively. Meanwhile, $E_{\text {Sunglass }}$ is largely affected by wavelengths. At $\lambda=0.35 \mu \mathrm{m}, E_{\text {Sunglass }}$ is in the range from 1.523 to 1.807 , while $E_{\text {Sunglass }}$ approaches 0 at $\lambda=0.7 \mu \mathrm{m}$. It can also be seen from Fig. 11 that $E_{\text {Sunglass }}>E_{\text {abs_lensing }}-1$ at $\lambda=0.35$ and $0.404 \mu \mathrm{m}$. Therefore, $E_{\text {abs_internal }}$ is less than 1 .

You et al. (2016) demonstrated that there are different wavelength dependencies for $\mathrm{BC}$ that is coated with absorbing and weakly absorbing materials. $E_{\text {abs }}$ for BC coated with humic acid was observed to vary from 3.0 to approximately 1.6 as $\lambda$ increased from 0.554 to $0.84 \mu \mathrm{m}$, while it seemed to
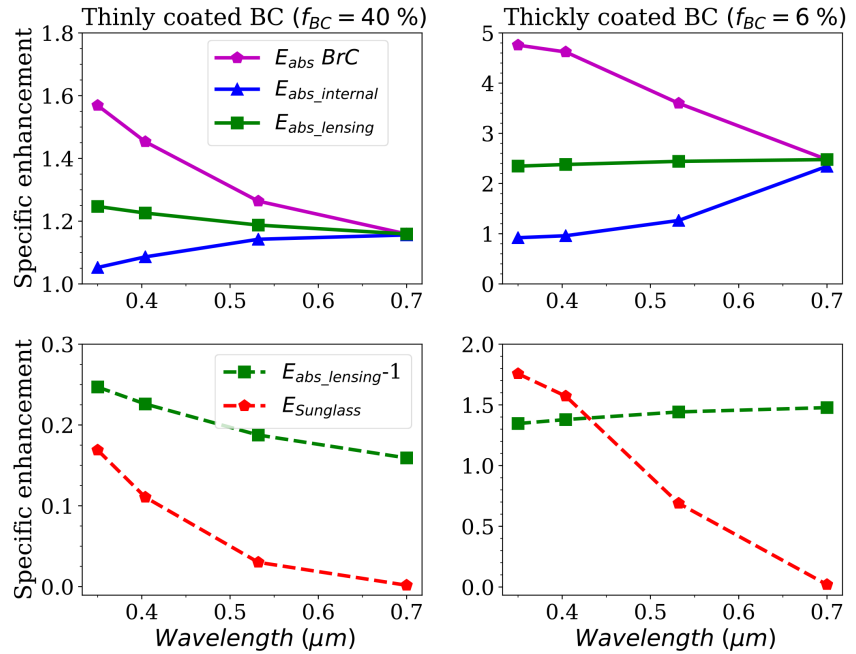

Figure 12. Comparison of $\mathrm{BC}$ coated with non-absorbing materials and that coated with $\operatorname{BrC}\left(r_{\mathrm{g}}=0.06 \mu \mathrm{m}, \sigma_{\mathrm{g}}=1.5\right) . D_{\mathrm{f}}=2.2$ and $D_{\mathrm{f}}=2.6$ were assumed for thinly coated and thickly coated BC, respectively.

be essentially wavelength independent for BC that is coated with sodium chloride. Figure 12 compares the wavelength dependencies of $\mathrm{BC}$ coated with non-absorbing materials and $\mathrm{BrC}$. For thinly coated BC, there are substantial wavelength dependencies for $\mathrm{BC}$ coated with $\mathrm{BrC}$. By setting $f_{\mathrm{BC}}$ to be $40 \%, E_{\text {abs }}$ increases from 1.15 to 1.57 with $\lambda$ varying from 0.7 to $0.35 \mu \mathrm{m}$, which results in an approximately $49.6 \%$ increase. However, when coated with non-absorbing materials, $E_{\text {abs }}$ exhibits small wavelength dependences. This leads to approximate $8.7 \%$ increases as $\lambda$ decreases from 0.7 to $0.35 \mu \mathrm{m}$. Furthermore, for thickly coated BC, $E_{\text {abs }}$ is significantly wavelength dependent for $\mathrm{BC}$ with $\mathrm{BrC}$ coatings. The decrease in $\lambda$ from 0.7 to $0.35 \mu \mathrm{m}$ would result in an approximately $100 \%$ increase in $E_{\text {abs }}$, while $E_{\text {abs }}$ seems to be essentially wavelength independent for $\mathrm{BC}$ with non-absorbing coatings $\left(E_{\text {abs_lensing }}\right)$; it is approximately 2.4 when $f_{\mathrm{BC}}=$ $6 \%$, which is consistent with the value reported by Zhang et al. (2017). The differences of $E_{\text {abs_lensing }}$ of thickly coated $\mathrm{BC}$ between $\lambda=0.35$ and $0.7 \mu \mathrm{m}$ are below $6.2 \%$. Therefore, the variation in $k_{\mathrm{BrC}}$ should be mainly responsible for the significant wavelength dependencies of $E_{\mathrm{abs}}$ for BC with $\mathrm{BrC}$ coatings when the wavelength is long. For ultraviolet wavelengths ( $\lambda$ from 0.35 to $0.404 \mu \mathrm{m}$ ), wavelength dependence of $E_{\text {abs }}$ is relatively small, as the $E_{\text {abs }}$ may increase with wavelength when $k_{\mathrm{BrC}}$ is fixed at a large value (see Fig. 2), which can reduce the wavelength dependence. Therefore, the contribution of $k_{\mathrm{BrC}}$ to the wavelength dependence should be further analyzed in ultraviolet wavelengths in the future.

In addition, the $E_{\text {abs_internal }}$ of $\mathrm{BC}$ coated with $\mathrm{BrC}$ is also significantly wavelength dependent. Fixing $f_{\mathrm{BC}}=40 \%$ and $6 \%$, respectively, with $\lambda$ varying from 0.35 to $0.7 \mu \mathrm{m}$, 
$E_{\text {abs_internal }}$ increases from 1.05 to 1.18 and from approximately 0.92 to 2.3 , respectively. $E_{\text {abs_lensing }}-1$ and $E_{\text {Sunglass }}$ are also compared in Fig. 12. $E_{\text {Sunglass }}$ decreases significantly with $\lambda$ for both thinly and thickly coated BC. For thinly coated BC, $E_{\text {abs_lensing }}-1$ is larger than $E_{\text {Sunglass }}$ for all wavelengths. However, $E_{\text {Sunglass }}$ can be stronger than $E_{\text {abs_lensing }}-1$ in the ultraviolet region for thickly coated $\mathrm{BC}$. This indicates that the total absorption of $\mathrm{BC}$ and $\mathrm{BrC}$ is weakened by internal mixing. Therefore, the sunglasses effect should also be noticed for the estimation of aerosol absorption.

\section{Summary and discussion}

Using the MSTM method, the $E_{\text {abs }}$ and $E_{\text {abs_lensing }}$ of BC with $\mathrm{BrC}$ coatings were investigated at $\lambda=0.35,0.404$, 0.532 , and $0.7 \mu \mathrm{m}$, respectively. The main findings of this work are as follows.

1. Generally, $E_{\mathrm{abs}}$ increases with $k_{\mathrm{BrC}}$ while $E_{\text {abs_interanl }}$ decreases as $k_{\mathrm{BrC}}$ becomes larger. For the thinly coated $\mathrm{BC}, E_{\text {abs_internal }}$ is greater than 1 due to the enhancements of the lensing effects. However, for thickly coated $\mathrm{BC}$, the $E_{\text {abs_internal }}$ can be less than 1 . This indicates the total absorption of $\mathrm{BrC}$ and $\mathrm{BC}$ is less than the sum of $\mathrm{BrC}$ and $\mathrm{BC}$ absorption individually, which is opposite to $\mathrm{BC}$ that is coated with weakly absorbing coatings. This phenomenon may be caused by the blocking effects of outer coatings. As the absorption of coatings increases, less light can penetrate into $\mathrm{BC}$ materials. Therefore, the total absorption of $\mathrm{BrC}$ and $\mathrm{BC}$ is weakened, resulting in $E_{\text {abs_internal }}$ of less than 1 . This effect is named the "sunglasses effect" in this study.

2. $C_{\mathrm{abs}}$ of thinly coated $\mathrm{BC}$ is underestimated by the coreshell sphere model in the ultraviolet region while it is overestimated in the visible region. In addition, the ratio of $C_{\mathrm{abs}}$ of thinly coated $\mathrm{BC}$ to that of the core-shell sphere model increases with $k_{\mathrm{BrC}}$. $E_{\mathrm{abs}}$ of thinly coated $\mathrm{BC}$ is enhanced by the core-shell sphere while the enhancements are alleviated by increasing $k_{\mathrm{BrC}}$. There are different dependencies for thickly coated BC. $C_{\text {abs }}$ of thickly coated $\mathrm{BC}$ is underestimated by the core-shell sphere model for all wavelengths while the underestimation becomes negligible as $k_{\mathrm{BrC}}$ becomes very large. $E_{\text {abs }}$ of thickly coated BC with non-absorbing materials is underestimated by the core-shell assumption. However, the ratio of $E_{\mathrm{abs}}$ of thickly coated BC to the coreshell sphere model decreases with increasing $k_{\mathrm{BrC}}$, and $E_{\text {abs }}$ is enhanced by the core-shell sphere in the visible region, when the absorption of coatings is large.

3. To make our calculation more consistent with real circumstance, the bulk absorption was calculated and the $k_{\mathrm{BrC}}$ is selected by interpolation based on the study of
Kirchstetter et al. (2004). For thinly coated BC, the effects of size distribution on $E_{\text {abs }}$ are not obvious. The uncertainties of size distribution result in $E_{\text {abs }}$ differences of less than $2.56 \%, 2.52 \%, 2.32 \%$, and $2.16 \%$ for $\lambda=0.35,0.404,0.532$, and $0.7 \mu \mathrm{m}$, respectively. However, $E_{\text {abs }}$ of thickly coated BC is quite sensitive to the size distribution. $E_{\text {abs }}$ differences of approximately $92 \%$ can be obtained as $r_{\mathrm{g}}$ and $\sigma_{\mathrm{g}}$ vary for $\lambda=0.35 \mu \mathrm{m}$. In addition, different from $E_{\text {abs }}$ of 2.2-2.4 for thickly coated BC with weakly absorbing coatings, $E_{\mathrm{abs}}$ of 3.4-5.4 is observed for $\mathrm{BC}$ with $\mathrm{BrC}$ coatings at $\lambda=$ $0.35 \mu \mathrm{m}$ as $M_{\mathrm{R}}$ is in the range of $\sim 6.6-13.9$. Specifically, as $M_{\mathrm{R}}$ increases to approximately $13.9, E_{\mathrm{abs}}$ of larger than 3.96 can be observed at $0.532 \mu \mathrm{m}$, which is a little higher than the commonly measured $E_{\mathrm{abs}}$ of $1.05-3.5$ at this wavelength. For thinly coated BC, $E_{\text {abs }}$ of $\mathrm{BC}$ with weakly absorbing coatings is in the range of approximately $\sim 1-1.3$ for $\lambda=0.7 \mu \mathrm{m}$ (i.e., BC with weakly absorbing coatings) while a wider range of $\sim 1-$ 2.5 is obtained for $\lambda=0.35 \mu \mathrm{m}$. In summary, the $E_{\mathrm{abs}}$ range of $\mathrm{BC}$ with $\mathrm{BrC}$ coatings is much wider than that of $\mathrm{BC}$ with non-absorbing coatings.

4. The sunglasses effect and lensing effect are compared at different wavelengths. $E_{\text {sunglass }}$ is less than $E_{\text {abs_lensing }}-$ 1 for thinly coated BC. This indicates the blocking of the sunglasses effect is less than the enhancement of the lensing effect, so the $E_{\text {internal }}>1$ for thinly coated BC. However, $E_{\text {sunglass }}$ can be larger than $E_{\text {abs_lensing }}-1$ in the ultraviolet region for thickly coated BC, which leads to $E_{\text {internal }}<1$. Therefore, the absorption of BC thickly coated with $\mathrm{BrC}$ can be less than an external mixture of $\mathrm{BC}$ and $\mathrm{BrC}$. In the visible region, $E_{\text {sunglass }}$ is less than $E_{\text {abs_lensing }}-1$ due to the small sunglasses effect.

5. $E_{\mathrm{abs}}$ of $\mathrm{BC}$ with $\mathrm{BrC}$ coatings is more wavelength dependent than that with non-absorbing coatings. For thinly coated BC, $E_{\text {abs }}$ of BC with non-absorbing coatings leads to an approximately $8.7 \%$ increase as $\lambda$ decreases from 0.7 to $0.35 \mu \mathrm{m}$ while the difference can reach approximately $50 \%$ for $\mathrm{BC}$ with $\mathrm{BrC}$ coatings. For thickly coated $\mathrm{BC}$, the decrease in $\lambda$ from 0.7 to $0.35 \mu \mathrm{m}$ would result in an approximately $100 \%$ increase in $E_{\mathrm{abs}}$ for BC with $\mathrm{BrC}$ coatings. However, $E_{\mathrm{abs}}$ of $\mathrm{BC}$ with non-absorbing coatings seems to be to be essentially wavelength independent. In addition, for thinly coated BC, the effects of $D_{\mathrm{f}}$ are not obvious for $E_{\mathrm{abs}}$ and

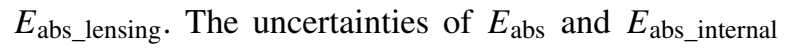
caused by $D_{\mathrm{f}}$ all are less than $5 \%$.

In this work, complex morphologies and mixing states are considered. Although current climate models do not simulate any morphological information of aerosols, many laboratory studies have been conducted to investigate the $\mathrm{BC}$ morphologies in different mixing states and in different regions. Therefore, our calculations can be applied according 
to specific mixing states (such as composition ratios) and regions. However, we acknowledge that the understanding of the relation between $\mathrm{BC}$ morphology and the composition ratio is still limited. Therefore, further laboratory investigations for the coated $\mathrm{BC}$ morphologies should be conducted in the future.

Data availability. Our data are all exhibited in the figures. We have only a supplementary pdf file, which is available on the ACP website.

Supplement. The supplement related to this article is available online at: https://doi.org/10.5194/acp-18-16897-2018-supplement.

Author contributions. JL and QZ conceived the presented idea. JL developed the models, performed the computations, and wrote the paper. YZ and FW verified the simulation methods and results. QZ revised the paper and supervised the findings of this work. All authors discussed the results and contributed to the final paper.

Competing interests. The authors declare that they have no conflict of interest.

Acknowledgements. This work was financially supported by the National Key Research and Development Plan (grant nos. 2016YFC0800100 and 2017YFC0805100), National Natural Science Foundation of China (grant nos. 41675024 and U1733126), and Fundamental Research Funds for the Central Universities (grant no. WK2320000035). We particularly thank Daniel W. Mackowski and Michael I. Mishchenko for the MSTM code. We also acknowledge the support of the supercomputing center of USTC. We particularly thank the three anonymous reviewers for their constructive suggestions.

Edited by: James Allan

Reviewed by: three anonymous referees

\section{References}

Adachi, K. and Buseck, P. R.: Internally mixed soot, sulfates, and organic matter in aerosol particles from Mexico City, Atmos. Chem. Phys., 8, 6469-6481, https://doi.org/10.5194/acp-8-64692008, 2008.

Adachi, K., Chung, S. H., and Buseck, P. R.: Shapes of soot aerosol particles and implications for their effects on climate, J. Geophys. Res.-Atmos., 115, D15206, https://doi.org/10.1029/2009JD012868, 2010.

Alexander, D. T. L., Crozier, P. A., and Anderson, J. R.: Brown carbon spheres in East Asian outflow and their optical properties, Science, 321, 833-836, 2008.

Andreae, M. O. and Gelencsér, A.: Black carbon or brown carbon? The nature of light-absorbing carbonaceous aerosols, At- mos. Chem. Phys., 6, 3131-3148, https://doi.org/10.5194/acp-63131-2006, 2006.

Bergstrom, R. W.: Predictions of the spectral absorption and extinction coefficients of an urban air pollution aerosol model, Atmos. Environ., 6, 247-258, https://doi.org/10.1016/00046981(72)90083-2, 1972.

Bi, L. and Yang, P.: Tunneling effects in electromagnetic wave scattering by nonspherical particles: A comparison of the Debye series and physical-geometric optics approximations, J. Quant. Spectrosc. Ra., 178, 93-107, 2016.

Bond, T. C. and Bergstrom, R. W.: Light absorption by carbonaceous particles: An investigative review, Aerosol Sci. Tech., 40, 27-67, 2006.

Bond, T. C., Covert, D. S., Kramlich, J. C., Larson, T. V., and Charlson, R. J.: Primary particle emissions from residential coal burning: Optical properties and size distributions, J. Geophys. Res.-Atmos., 107, 8347, https://doi.org/10.1029/2001JD000571, 2002.

Bond, T. C., Habib, G., and Bergstrom, R. W.: Limitations in the enhancement of visible light absorption due to mixing state, J. Geophys. Res.-Atmos., 111, D20211, https://doi.org/10.1029/2006JD007315., 2006.

Bond, T. C., Doherty, S. J., Fahey, D. W., Forster, P. M., Berntsen, T., DeAngelo, B. J., Flanner, M. G., Ghan, S., Karcher, B., Koch, D., Kinne, S., Kondo, Y., Quinn, P. K., Sarofim, M. C., Schultz, M. G., Schulz, M., Venkataraman, C., Zhang, H., Zhang, S., Bellouin, N., Guttikunda, S. K., Hopke, P. K., Jacobson, M. Z., Kaiser, J. W., Klimont, Z., Lohmann, U., Schwarz, J. P., Shindell, D., Storelvmo, T., Warren, S. G., and Zender, C. S.: Bounding the role of black carbon in the climate system: A scientific assessment, J. Geophys. Res.-Atmos., 118, 5380-5552, 2013.

Cappa, C. D., Onasch, T. B., Massoli, P., Worsnop, D. R., Bates, T. S., Cross, E. S., Davidovits, P., Hakala, J., Hayden, K. L., Jobson, B. T., Kolesar, K. R., Lack, D. A., Lerner, B. M., Li, S. M., Mellon, D., Nuaaman, I., Olfert, J. S., Petaja, T., Quinn, P. K., Song, C., Subramanian, R., Williams, E. J., and Zaveri, R. A.: Radiative Absorption Enhancements Due to the Mixing State of Atmospheric Black Carbon, Science, 337, 1078-1081, 2012.

Chakrabarty, R. K., Moosmuller, H., Garro, M. A., Arnott, W. P., Walker, J., Susott, R. A., Babbitt, R. E., Wold, C. E., Lincoln, E. N., and Hao, W. M.: Emissions from the laboratory combustion of wildland fuels: Particle morphology and size, J. Geophys. Res.-Atmos., 111, D07204, https://doi.org/10.1029/2005JD006659, 2006.

Chen, B., Bai, Z., Cui, X. J., Chen, J. M., Andersson, A., and Gustafsson, O.: Light absorption enhancement of black carbon from urban haze in Northern China winter, Environ. Pollut., 221, 418-426, 2017.

Cheng, T. H., Wu, Y., and Chen, H.: Effects of morphology on the radiative properties of internally mixed light absorbing carbon aerosols with different aging status, Opt. Express, 22, 1590415917, 2014.

Cheng, T. H., Wu, Y., Gu, X. F., and Chen, H.: Effects of mixing states on the multiple-scattering properties of soot aerosols, Opt. Express, 23, 10808-10821, 2015.

Cheng, Y., He, K. B., Engling, G., Weber, R., Liu, J. M., Du, Z. Y., and Dong, S. P.: Brown and black carbon in Beijing aerosol: Implications for the effects of brown coating on light absorption by black carbon, Sci. Total Environ., 599, 1047-1055, 2017. 
China, S., Mazzoleni, C., Gorkowski, K., Aiken, A. C., and Dubey, M. K.: Morphology and mixing state of individual freshly emitted wildfire carbonaceous particles, Nat. Commun., 4, 2122, https://doi.org/10.1038/ncomms3122, 2013.

China, S., Salvadori, N., and Mazzoleni, C.: Effect of Traffic and Driving Characteristics on Morphology of Atmospheric Soot Particles at Freeway On-Ramps, Environ. Sci. Technol., 48, 3128-3135, 2014.

Chung, C. E., Ramanathan, V., and Decremer, D.: Observationally constrained estimates of carbonaceous aerosol radiative forcing, P. Natl. Acad. Sci. USA, 109, 11624-11629, 2012.

Coz, E. and Leck, C.: Morphology and state of mixture of atmospheric soot aggregates during the winter season over Southern Asia-a quantitative approach, Tellus B, 63, 107-116, 2011 a.

Coz, E. and Leck, C.: Morphology and state of mixture of atmospheric soot aggregates during the winter season over Southern Asia-a quantitative approach, Tellus B, 63, 107-116, $2011 \mathrm{~b}$.

Cui, X. J., Wang, X. F., Yang, L. X., Chen, B., Chen, J. M., Andersson, A., and Gustafsson, O.: Radiative absorption enhancement from coatings on black carbon aerosols, Sci. Total Environ., 551, 51-56, 2016.

Draine, B. T. and Flatau, P. J.: Discrete-Dipole Approximation for Scattering Calculations, J. Opt. Soc. Am., 11, 1491-1499, 1994.

Forster, P., Ramaswamy, V., Artaxo, P., Berntsen, T., Betts, R., Fahey, D. W., Haywood, J., Lean, J., Lowe, D. C., Myhre, G., Nganga, J., Prinn, R., Raga, G., Schultz, M., and Van Dorland, $\mathrm{R}$.: Changes in atmospheric constituents and in radiative forcing, Chap. 2, in: Climate Change 2007, The Physical Science Basis, Cambridge University Press, Cambridge, UK, 2007.

Fuller, K. A., Malm, W. C., and Kreidenweis, S. M.: Effects of mixing on extinction by carbonaceous particles, J. Geophys. Res.Atmos., 104, 15941-15954, 1999a.

Fuller, K. A., Malm, W. C., and Kreidenweis, S. M.: Effects of mixing on extinction by carbonaceous particles, J. Geophys. Res.Atmos., 104, 15941-15954, 1999b.

He, C., Liou, K.-N., Takano, Y., Zhang, R., Levy Zamora, M., Yang, P., Li, Q., and Leung, L. R.: Variation of the radiative properties during black carbon aging: theoretical and experimental intercomparison, Atmos. Chem. Phys., 15, 11967-11980, https://doi.org/10.5194/acp-15-11967-2015, 2015.

He, C. L., Takano, Y., Liou, K. N., Yang, P., Li, Q. B., and Mackowski, D. W.: Intercomparison of the GOS approach, superposition T-matrix method, and laboratory measurements for black carbon optical properties during aging, J. Opt. Soc. Am., 184, 287-296, 2016.

Hentschel, H. G. E.: Fractal Dimension of Generalized DiffusionLimited Aggregates, Phys. Rev. Lett., 52, 212-215, 1984.

Horvath, H.: Atmospheric Light-Absorption - a Review, Atmos. Environ. A-Gen., 27, 293-317, 1993.

Jacobson, M. Z.: Strong radiative heating due to the mixing state of black carbon in atmospheric aerosols, Nature, 409, 695-697, 2001.

Janzen, J.: Extinction of Light by Highly Nonspherical Strongly Absorbing Colloidal Particles - Spectrophotometric Determination of Volume Distributions for Carbon-Blacks, Appl. Optics, 19, 2977-2985, 1980.

Jensen, M. H., Levermann, A., Mathiesen, J., and Procaccia, I.: Multifractal structure of the harmonic measure of diffusion-limited aggregates, Phys. Rev. E, 65, 046109, https://doi.org/10.1103/PhysRevE.65.046109, 2002.

Kahnert, M.: Modelling the optical and radiative properties of freshly emitted light absorbing carbon within an atmospheric chemical transport model, Atmos. Chem. Phys., 10, 1403-1416, https://doi.org/10.5194/acp-10-1403-2010, 2010a.

Kahnert, M.: On the Discrepancy between Modeled and Measured Mass Absorption Cross Sections of Light Absorbing Carbon Aerosols, Aerosol Sci. Tech., 44, 453-460, 2010 b.

Kahnert, M.: Optical properties of black carbon aerosols encapsulated in a shell of sulfate: comparison of the closed cell model with a coated aggregate model, Opt. Express, 25, 24579-24593, 2017.

Kahnert, M., Nousiainen, T., Lindqvist, H., and Ebert, M.: Optical properties of light absorbing carbon aggregates mixed with sulfate: assessment of different model geometries for climate forcing calculations, Opt. Express, 20, 10042-10058, https://doi.org/10.1364/OE.20.010042, 2012.

Kirchstetter, T. W., Novakov, T., and Hobbs, P. V.: Evidence that the spectral dependence of light absorption by aerosols is affected by organic carbon, J. Geophys. Res.-Atmos., 109, D21208, https://doi.org/10.1029/2004JD004999, 2004.

Koylu, U. O., Faeth, G. M., Farias, T. L., and Carvalho, M. G.: Fractal and Projected Structure Properties of Soot Aggregates, Combus. Flame, 100, 621-633, 1995.

Krishnan, R. and Ramanathan, V.: Evidence of surface cooling from absorbing aerosols, Geophys. Res. Lett., 29, 1340, https://doi.org/10.1029/2002GL014687, 2002.

Lack, D. A., Cappa, C. D., Cross, E. S., Massoli, P., Ahern, A. T., Davidovits, P., and Onasch, T. B.: Absorption Enhancement of Coated Absorbing Aerosols: Validation of the Photo-Acoustic Technique for Measuring the Enhancement, Aerosol Sci. Tech., 43, 1006-1012, 2009.

Laczik, Z.: Discrete-dipole-approximation-based light-scattering calculations for particles with a real refractive index smaller than unity, Appl. Optics, 35, 3736-3745, 1996.

Li, J., Liu, C., Yin, Y., and Kumar, K. R.: Numerical investigation on the Ångström Exponent of black carbon aerosol, J. Geophys. Res.-Atmos., 121, 3506-3518, 2016.

Liou, K. N., Takano, Y., and Yang, P.: Light absorption and scattering by aggregates: Application to black carbon and snow grains, J. Quant. Spectrosc. Ra., 112, 1581-1594, 2011.

Liu, C., Chung, C. E., Yin, Y., and Schnaiter, M.: The absorption Ångström exponent of black carbon: from numerical aspects, Atmos. Chem. Phys., 18, 6259-6273, https://doi.org/10.5194/acp18-6259-2018, 2018.

Liu, D. T., Taylor, J. W., Young, D. E., Flynn, M. J., Coe, H., and Allan, J. D.: The effect of complex black carbon microphysics on the determination of the optical properties of brown carbon, Geophys. Res. Lett., 42, 613-619, $2015 \mathrm{a}$.

Liu, D. T., Whitehead, J., Alfarra, M. R., Reyes-Villegas, E., Spracklen, D. V., Reddington, C. L., Kong, S. F., Williams, P. I., Ting, Y. C., Haslett, S., Taylor, J. W., Flynn, M. J., Morgan, W. T., McFiggans, G., Coe, H., and Allan, J. D.: Black-carbon absorption enhancement in the atmosphere determined by particle mixing state, Nat. Geosci., 10, 184-188, 2017.

Liu, L. and Mishchenko, M. I.: Effects of aggregation on scattering and radiative properties of soot aerosols, J. Geophys. Res.- 
Atmos., 110, D11211, https://doi.org/10.1029/2004JD005649, 2005.

Liu, S., Aiken, A. C., Gorkowski, K., Dubey, M. K., Cappa, C. D., Williams, L. R., Herndon, S. C., Massoli, P., Fortner, E. C., Chhabra, P. S., Brooks, W. A., Onasch, T. B., Jayne, J. T., Worsnop, D. R., China, S., Sharma, N., Mazzoleni, C., Xu, L., Ng, N. L., Liu, D., Allan, J. D., Lee, J. D., Fleming, Z. L., Mohr, C., Zotter, P., Szidat, S., and Prevot, A. S. H.: Enhanced light absorption by mixed source black and brown carbon particles in UK winter, Nat. Commun., 6, 8435, https://doi.org/10.1038/ncomms9435., 2015b.

Liu, X., Easter, R. C., Ghan, S. J., Zaveri, R., Rasch, P., Shi, X., Lamarque, J.-F., Gettelman, A., Morrison, H., Vitt, F., Conley, A., Park, S., Neale, R., Hannay, C., Ekman, A. M. L., Hess, P., Mahowald, N., Collins, W., Iacono, M. J., Bretherton, C. S., Flanner, M. G., and Mitchell, D.: Toward a minimal representation of aerosols in climate models: description and evaluation in the Community Atmosphere Model CAM5, Geosci. Model Dev., 5, 709-739, https://doi.org/10.5194/gmd-5-709-2012, 2012.

Luo, J., Zhang, Y., Wang, F., Wang, J., and Zhang, Q.: Applying machine learning to estimate the optical properties of black carbon fractal aggregates, J. Opt. Soc. Am., 215, 1-8, https://doi.org/10.1016/j.jqsrt.2018.05.002, 2018a.

Luo, J., Zhang, Y., Zhang, Q., Wang, F., Liu, J., and Wang, J.: Sensitivity analysis of morphology on radiative properties of soot aerosols, Opt. Express, 26, A420-A432, https://doi.org/10.1364/OE.26.00A420, 2018b.

Luo, J., Zhang, Y. M., and Zhang, Q. X.: A model study of aggregates composed of spherical soot monomers with an acentric carbon shell, J. Quant. Spectrosc. Ra., 205, 184-195, 2018c.

Ma, X., Yu, F., and Luo, G.: Aerosol direct radiative forcing based on GEOS-Chem-APM and uncertainties, Atmos. Chem. Phys., 12, 5563-5581, https://doi.org/10.5194/acp-125563-2012, 2012.

Mackowski, D. W.: MSTM Version 3.0: April 2013, available at: http://www.eng.auburn.edu/ dmckwski/scatcodes/ (last access: 10 October 2017), 2013.

Mackowski, D. W. and Mishchenko, M. I.: A multiple sphere Tmatrix Fortran code for use on parallel computer clusters, J. Quant. Spectrosc. Ra., 112, 2182-2192, 2011.

Medalia, A. I. and Richards, L. W.: Tinting Strength of Carbon-Black, J. Colloid. Interf. Sci., 40, 233-252, https://doi.org/10.1016/0021-9797(72)90013-6, 1972.

Mie, G.: Beiträge zur Optik trüber Medien, speziell kolloidaler Metallösungen, Ann. Phys., 330, 377-445, https://doi.org/10.1002/andp.19083300302, 1908.

Mishchenko, M. I. and Yurkin, M. A.: On the concept of random orientation in far-field electromagnetic scattering by nonspherical particles, Opt. Lett., 42, 494-497, 2017.

Mishchenko, M. I., Travis, L. D., and Lacis, A. A.: Scattering, absorption, and emission of light by small particles, Cambridge university press, Cambridge, UK, 2002.

Mishchenko, M. I., Liu, L., Travis, L. D., and Lacis, A. A.: Scattering and radiative properties of semi-external versus external mixtures of different aerosol types, J. Opt. Soc. Am., 88, 139147, 2004.

Mishchenko, M. I., Liu, L., Cairns, B., and Mackowski, D. W.: Optics of water cloud droplets mixed with black-carbon aerosols, Opt. Lett., 39, 2607-2610, 2014.
Moffet, R. C. and Prather, K. A.: In-situ measurements of the mixing state and optical properties of soot with implications for radiative forcing estimates, P. Natl. Acad. Sci. USA, 106, 11872 11877, 2009.

Moosmuller, H., Chakrabarty, R. K., and Arnott, W. P.: Aerosol light absorption and its measurement: A review, J. Quant. Spectrosc. Ra., 110, 844-878, 2009.

Nakao, S., Tang, P., Tang, X. C., Clark, C. H., Qi, L., Seo, E., Asa-Awuku, A., and Cocker, D.: Density and elemental ratios of secondary organic aerosol: Application of a density prediction method, Atmos. Environ., 68, 273-277, 2013.

Naoe, H., Hasegawa, S., Heintzenberg, J., Okada, K., Uchiyama, A., Zaizen, Y., Kobayashi, E., and Yamazaki, A.: State of mixture of atmospheric submicrometer black carbon particles and its effect on particulate light absorption, Atmos. Environ., 43, 1296-1301, 2009.

Schnaiter, M., Linke, C., Mohler, O., Naumann, K. H., Saathoff, H., Wagner, R., Schurath, U., and Wehner, B.: Absorption amplification of black carbon internally mixed with secondary organic aerosol, J. Geophys. Res.-Atmos., 110, D19204, https://doi.org/10.1029/2005JD006046, 2005.

Schwarz, J. P., Spackman, J. R., Fahey, D. W., Gao, R. S., Lohmann, U., Stier, P., Watts, L. A., Thomson, D. S., Lack, D. A., Pfister, L., Mahoney, M. J., Baumgardner, D., Wilson, J. C., and Reeves, J. M.: Coatings and their enhancement of black carbon light absorption in the tropical atmosphere, J. Geophys. Res.-Atmos., 113, D03203, https://doi.org/10.1029/2007JD009042, 2008.

Shamjad, P. M., Satish, R. V., Thamban, N. M., Rastogi, N., and Tripathi, S. N.: Absorbing Refractive Index and Direct Radiative Forcing of Atmospheric Brown Carbon over Gangetic Plain, Acs Earth and Space Chemistry, 2, 31-37, 2018.

Sorensen, C. M.: Light scattering by fractal aggregates: A review, Aerosol Sci. Tech., 35, 648-687, 2001.

Sorensen, C. M. and Roberts, G. C.: The prefactor of fractal aggregates, J. Colloid. Interf. Sci., 186, 447-452, 1997.

Strawa, A. W., Drdla, K., Ferry, G. V., Verma, S., Pueschel, R. F., Yasuda, M., Salawitch, R. J., Gao, R. S., Howard, S. D., Bui, P. T., Loewenstein, M., Elkins, J. W., Perkins, K. K., and Cohen, R.: Carbonaceous aerosol (Soot) measured in the lower stratosphere during POLARIS and its role in stratospheric photochemistry, J. Geophys. Res.-Atmos., 104, 26753-26766, 1999.

Taflove, A. and Hagness, S. C.: Computational electrodynamics: the finite-difference time-domain method, Artech house, Norwood, MA, 2005.

Thouy, R. and Jullien, R.: A Cluster-Cluster Aggregation Model with Tunable Fractal Dimension, J. Phys. A-Math. Gen., 27, 2953-2963, 1994.

Wang, Q. Y., Huang, R.-J., Cao, J. J., Tie, X. X., Ni, H. Y., Zhou, Y. Q., Han, Y. M., Hu, T. F., Zhu, C. S., Feng, T., Li, N., and Li, J. D.: Black carbon aerosol in winter northeastern Qinghai-Tibetan Plateau, China: the source, mixing state and optical property, Atmos. Chem. Phys., 15, 13059-13069, https://doi.org/10.5194/acp-15-13059-2015, 2015.

Wang, Y. Y., Liu, F. S., He, C. L., Bi, L., Cheng, T. H., Wang, Z. L., Zhang, H., Zhang, X. Y., Shi, Z. B., and Li, W. J.: Fractal Dimensions and Mixing Structures of Soot Particles during Atmospheric Processing, Environ. Sci. Tech. Lett., 4, 487-493, 2017.

Wentzel, M., Gorzawski, H., Naumann, K. H., Saathoff, H., and Weinbruch, S.: Transmission electron microscopical and aerosol 
dynamical characterization of soot aerosols, J. Aerosol Sci., 34, 1347-1370, 2003.

Woźniak, M.: Characterization of nanoparticle aggregates with light scattering techniques, Thesis, Aix-Marseille Université, Provence, France, available at: https://tel.archives-ouvertes.fr/ tel-00747711 (last access: 19 November 2018), 2012.

Wu, Y., Cheng, T. H., Gu, X. F., Zheng, L. J., Chen, H., and Xu, H.: The single scattering properties of soot aggregates with concentric core-shell spherical monomers, J. Opt. Soc. Am., 135, 9-19, 2014.

Xu, X., Zhao, W., Zhang, Q., Wang, S., Fang, B., Chen, W., Venables, D. S., Wang, X., Pu, W., Wang, X., Gao, X., and Zhang, W.: Optical properties of atmospheric fine particles near Beijing during the HOPE-J ${ }^{3}$ A campaign, Atmos. Chem. Phys., 16, 6421-6439, https://doi.org/10.5194/acp-16-6421-2016, 2016.

$\mathrm{Xu}, \mathrm{Y}$. L.: Calculation of the addition coefficients in electromagnetic multisphere-scattering theory (vol. 127, p. 285, 1996), J. Comput. Phys., 134, 200-200, 1997.

Xu, Y. L. and Gustafson, B. A. S.: A generalized multiparticle Miesolution: further experimental verification, J. Quant. Spectrosc. Ra., 70, 395-419, 2001.

Yang, P., Wei, H. L., Kattawar, G. W., Hu, Y. X., Winker, D. M., Hostetler, C. A., and Baum, B. A.: Sensitivity of the backscattering Mueller matrix to particle shape and thermodynamic phase, Appl. Optics, 42, 4389-4395, 2003.

Yee, K.: Numerical solution of initial boundary value problems involving Maxwell's equations in isotropic media, IEEE T. Antenn. Propag., 14, 302-307, 1966.

You, R., Radney, J. G., Zachariah, M. R., and Zangmeister, C. D.: Measured Wavelength-Dependent Absorption Enhancement of Internally Mixed Black Carbon with Absorbing and Nonabsorbing Materials, Environ. Sci. Technol., 50, 7982-7990, 2016.
Yurkin, M. A. and Hoekstra, A. G.: The discrete dipole approximation: An overview and recent developments, J. Quant. Spectrosc. Ra., 106, 558-589, 2007.

Zhang, R. Y., Khalizov, A. F., Pagels, J., Zhang, D., Xue, H. X., and McMurry, P. H.: Variability in morphology, hygroscopicity, and optical properties of soot aerosols during atmospheric processing, P. Natl. Acad. Sci. USA, 105, 10291-10296, 2008 a.

Zhang, R. Y., Khalizov, A. F., Pagels, J., Zhang, D., Xue, H. X., and McMurry, P. H.: Variability in morphology, hygroscopicity, and optical properties of soot aerosols during atmospheric processing, P. Natl. Acad. Sci. USA, 105, 10291-10296, 2008b.

Zhang, X. L., Mao, M., Yin, Y., and Wang, B.: Absorption enhancement of aged black carbon aerosols affected by their microphysics: A numerical investigation, J. Opt. Soc. Am., 202, 90-97, 2017.

Zhang, X. L., Mao, M., Yin, Y., and Wang, B.: Numerical Investigation on Absorption Enhancement of Black Carbon Aerosols Partially Coated With Nonabsorbing Organics, J. Geophys. Res.Atmos., 123, 1297-1308, 2018.

Zhang, Y., Zhang, Q., Cheng, Y., Su, H., Kecorius, S., Wang, Z., Wu, Z., Hu, M., Zhu, T., Wiedensohler, A., and He, K.: Measuring the morphology and density of internally mixed black carbon with SP2 and VTDMA: new insight into the absorption enhancement of black carbon in the atmosphere, Atmos. Meas. Tech., 9, 1833-1843, https://doi.org/10.5194/amt-9-1833-2016, 2016. 